\title{
Thin Air Resulting in High Pressure: Mountain Sickness and Hypoxia-Induced Pulmonary Hypertension
}

\author{
Jan Grimminger, ${ }^{1,2,3}$ Manuel Richter, ${ }^{2,3,4}$ Khodr Tello, ${ }^{2,3}$ Natascha Sommer, \\ Henning Gall, ${ }^{2,3}$ and Hossein Ardeschir Ghofrani ${ }^{2,3,4,5}$ \\ ${ }^{1}$ Department of Internal Medicine, University Clinic Hamburg Eppendorf, University of Hamburg, Martinistrasse 52, \\ 20246 Hamburg, Germany \\ ${ }^{2}$ Department of Internal Medicine, Justus Liebig University Giessen, Universities of Giessen and Marburg Lung Center (UGMLC), \\ Klinikstrasse 33, 35392 Giessen, Germany \\ ${ }^{3}$ German Center for Lung Research (DZL), Giessen, Germany \\ ${ }^{4}$ Department of Pneumology, Kerckhoff Heart and Thoracic Center, Bad Nauheim, Germany \\ ${ }^{5}$ Department of Medicine, Imperial College London, London, UK \\ Correspondence should be addressed to Jan Grimminger; j.grimminger@uke.de
}

Received 17 November 2016; Revised 15 February 2017; Accepted 28 February 2017; Published 27 March 2017

Academic Editor: Stylianos Orfanos

Copyright (C) 2017 Jan Grimminger et al. This is an open access article distributed under the Creative Commons Attribution License, which permits unrestricted use, distribution, and reproduction in any medium, provided the original work is properly cited.

\begin{abstract}
With rising altitude the partial pressure of oxygen falls. This phenomenon leads to hypobaric hypoxia at high altitude. Since more than 140 million people permanently live at heights above $2500 \mathrm{~m}$ and more than 35 million travel to these heights each year, understanding the mechanisms resulting in acute or chronic maladaptation of the human body to these circumstances is crucial. This review summarizes current knowledge of the body's acute response to these circumstances, possible complications and their treatment, and health care issues resulting from long-term exposure to high altitude. It furthermore describes the characteristic mechanisms of adaptation to life in hypobaric hypoxia expressed by the three major ethnic groups permanently dwelling at high altitude. We additionally summarize current knowledge regarding possible treatment options for hypoxia-induced pulmonary hypertension by reviewing in vitro, rodent, and human studies in this area of research.
\end{abstract}

\section{The Importance of High Altitude Medicine}

With rising altitude, atmospheric pressure falls. The percentage of oxygen in the air (20.9\%) is mostly independent of region and height [1], but since gases (in contrast to liquids) are compressible, the partial pressure of oxygen $\left(\mathrm{PO}_{2}\right)$ falls with rising altitude, resulting in hypobaric hypoxia at high altitude $[2,3] . \mathrm{PO}_{2}$ at sea level is approximately $159 \mathrm{~mm} \mathrm{Hg}$, whereas on the peak of Mount Everest $\mathrm{PO}_{2}$ is only about $53 \mathrm{~mm} \mathrm{Hg}[4,5]$. Acute exposure to hypoxic conditions, dependent on the severity, may lead to acute mountain sickness (AMS) and even life-threatening conditions such as high altitude cerebral edema (HACE, which can occur as the end-stage of AMS) and high altitude pulmonary edema (HAPE) [6, 7]. Long-term exposure to hypobaric hypoxia may also lead to health problems in the form of chronic mountain sickness (CMS) [8]. Pulmonary hypertension (PH) occurs in several altitude-associated diseases including CMS and is a key feature of HAPE [9-11]. AMS as well as CMS occur at heights above $2500 \mathrm{~m}[6-8,12]$, and altitude is categorized based on such physiological changes (Table 1) [13].

With approximately 35 million people traveling to high altitude each year, as well as military and rescue personnel, the latter often without adequate time to acclimatize, knowledge of the acute forms of maladaptation to hypoxia as well as their treatment is important [14]. CMS as the chronic form of maladaptation to high altitude conditions is also not to be neglected as a healthcare problem, because there are currently more than 140 million people permanently living at altitudes above $2500 \mathrm{~m} \mathrm{[15].}$ 
TABLE 1: Categorization of altitude.

\begin{tabular}{lc}
\hline Altitude category & Height above sea level \\
\hline (I) Moderate altitude & $1500-2500 \mathrm{~m}$ \\
(II) High altitude & $2500-3500 \mathrm{~m}$ \\
(III) Very high altitude & $3500-5800 \mathrm{~m}$ \\
(IV) Extremely high altitude & $>5800 \mathrm{~m}$ \\
\hline
\end{tabular}

\section{Acute Reactions of the Cardiopulmonary System to Hypoxia}

2.1. Physiologic Response. Within the first seconds after exposure to hypoxia, the resting cardiac output (CO) is increased. In 1982, Naeije et al. [26] demonstrated that this phenomenon was entirely based on the rise of heart rate and that stroke volume remained unchanged [26]. Furthermore, the increase in $\mathrm{CO}$ matched the decrease in arterial oxygen concentration. This phenomenon only lasts for a few days. CO then returns almost to sea-level values, with heart rate remaining elevated and stroke volume decreasing $[27,28]$. One reason for this adaptation is an increase in sympathetic nervous system activity along with decreased parasympathetic activity [29, 30]. An additional response to hypoxia is a rise in breathing frequency as well as tidal volume, also known as the hypoxic ventilatory response (HVR). This mechanism can increase alveolar ventilation by as much as 5-fold. HVR is triggered through chemoreceptors located in the bifurcation of the carotid arteries and is a direct response to the decreased partial pressure of arterial oxygen $[4,31]$. Resting ventilation returns to low-altitude levels after several days [32].

Within the first hours of exposure to hypobaric hypoxia at high altitude, erythrocyte concentration increases because of a reduction in plasma volume due to dehydration [31]. The latter is caused by tachypnea in dry high-altitude air [33] and by increased diuresis $[34,35]$. After this immediate response, circulating erythropoietin levels become vastly elevated within the first 24-48 hours of exposure to hypoxia and return to baseline values by the end of the first week [36]. The resulting elevation in erythrocyte concentration can be seen after 3-4 weeks [37].

In order for all these compensatory mechanisms to work adequately, acclimatization to high altitude is necessary. It is therefore recommended that people traveling above $3000 \mathrm{~m}$ ascend only about 300-500 m per day with a day of rest every third to fourth day [7].

\subsection{Hypoxic Pulmonary Vasoconstriction: Clinical Significance} and Molecular Mechanisms. Acute and prolonged exposure to hypoxia, for example, during a stay at high altitude, results in increased pulmonary vascular resistance and increased afterload of the right ventricle due to a mechanism termed hypoxic pulmonary vasoconstriction (HPV), also known as the von-Euler-Liljestrand mechanism. HPV is induced below a $\mathrm{PO}_{2}$ of about $100 \mathrm{~mm} \mathrm{Hg}$ (depending on species) and has two phases: an initial pulmonary vasoconstriction occurs within seconds after the onset of hypoxia, peaks after several minutes, and then decreases; this is followed by a second prolonged phase of vasoconstriction which reaches a maximum after several hours and cannot be completely reversed after reexposure to normoxia, in contrast to the first acute phase $[38,39]$. Von Euler and Liljestrand described this effect in 1946 in the cat and were the first to speculate that this mechanism may be responsible for ventilation-perfusion matching during regional hypoxia in the lung [40]. Indeed, regional alveolar hypoxia (e.g., due to alveolar hypoventilation) results in constriction of precapillary vessels at the entrance of the pulmonary acinus [41], which serves to redistribute blood from poorly ventilated to well ventilated alveoli and thus decreases pulmonary shunt flow, in order to optimize arterial oxygenation. Despite many years of research, the underlying mechanisms of HPV are not completely understood. The trigger for acute HPV seems to be located in the pulmonary arterial smooth muscle cells (PASMC), while initiation of sustained HPV may also depend on the presence of the endothelium [42] which is also a major modulator of HPV (e.g., via release of nitric oxide [NO]). Although the role of the endothelium is not completely resolved, it is commonly accepted that HPV is an adaptive physiologic mechanism attributed to the lung itself, because HPV is preserved in patients after lung transplantation [43].

Mitochondria or other oxygen-consuming organelles or enzymes in the PASMC, such as reduced nicotinamide adenine dinucleotide phosphate (NADPH) oxidases, may sense hypoxia and transfer the signal via alteration of the level of reactive oxygen species (ROS) or the cellular redox state to sarcoplasmic and plasmalemmal ion channels, such as potassium channels, transient receptor potential channels, and L-type calcium channels, which cause an intracellular calcium increase and vasoconstriction. Prolonged HPV may also be regulated by calcium sensitization via rho kinase and an alteration in the adenosine triphosphate (ATP)/adenosine monophosphate (AMP) ratio. However, the exact sequence of signal transduction and the primary oxygen sensor remain unknown (see reviews [56-59]). Particularly, the exact role of ROS as mediators in HPV, the effect of hypoxia on their levels, and the identities of their interaction partners (e.g., phospholipases and protein kinases) are not completely understood. Although chronic hypoxia-induced alterations of the pulmonary vasculature involve other pathologic mechanisms in addition to HPV, the identification of mechanisms regulating HPV has helped to uncover novel therapeutic approaches for $\mathrm{PH}$ (e.g., targeting the $\mathrm{NO}$-cyclic guanosine monophosphate [cGMP] pathway with sildenafil) [60].

Moreover, HPV is of clinical significance, because decreased HPV (which can occur, for example, during anesthesia [61], pulmonary inflammation [e.g., sepsis [62]], or the hepatopulmonary syndrome [63]) can lead to arterial hypoxemia. By contrast, exaggerated global HPV can aggravate $\mathrm{PH}$, and inhomogeneous $\mathrm{HPV}$ may contribute to the development of HAPE as described in a later section.

2.3. Acute Maladaptation. AMS is a combination of unspecific symptoms typically occurring in nonacclimatized individuals traveling above $2500 \mathrm{~m}$. Its onset is within the first 6-12 hours after arrival at high altitude [6, 7, 12]. Typical symptoms are headache followed by at least one more of the following symptoms: loss of appetite, nausea, vomiting, 
dizziness, insomnia, and fatigue $[6,7]$. Hitherto there are two hypotheses on the underlying pathogenesis.

(1) The fall in arterial oxygen concentration that accompanies an ascent to high altitude leads to an increase in the perfusion of the central nervous system (CNS) [64-66]. At the same time, autoregulation of the cerebral vessels is impaired $[67,68]$ and concentrations of circulating radicals $[67,69-71]$ and vascular endothelial growth factor (VEGF) [72] are increased. These circumstances may lead to increased permeability of the blood-brain barrier and thus result in extracellular edema. This hypothesis was supported by magnetic resonance imaging studies of healthy volunteers exposed to normobaric hypoxia [73, 74].

(2) Other data suggest that AMS is not associated with disruption of the blood-brain barrier [67]. Within the magnetic resonance imaging studies described above, asymptomatic individuals and those who developed AMS showed similar degrees of extracellular edema [73, 74], whereas those with AMS presented with an additional intracellular fluid accumulation, the quantity of which correlated with the degree of symptoms. In skeletal muscle cells, hypoxiainduced intracellular liquid accumulation has been shown to be related to impaired function of the $\mathrm{Na}^{+} \mathrm{K}^{+}$-ATPase [75]. The same impairment could be the cause of the previously mentioned intracellular fluid retention within the CNS [73]. Free circulating radicals are thought to reduce the activity of the $\mathrm{Na}^{+} \mathrm{K}^{+}$-ATPase, leading to an osmolarity-triggered fluid shift and thus swelling of astrocytes [73, 74]. The latter, via various mechanisms, is thought to lead to elevated NO synthesis [76] which, together with plasma membranedestabilizing free radicals as well as VEGF, would result in irritation of the sensory trigeminal fibers, triggering the typical headache [77].

AMS itself is benign but severe cases may, if countermeasures are not undertaken or if further ascent is undertaken, result in HACE [7]. Typical signs of the latter are awareness alteration and/or ataxia. Without therapy, death may occur through cerebral herniation. On a pathophysiological basis, extravasation due to hyperperfusion is thought to contribute [6]. However, keeping the known pathomechanism of AMS in mind, cytotoxic edema will also be present in HACE [78]. The major contributor to the increased intracranial pressure is thought to be the extracellular fluid shift [79].

Exposure to hypoxia (normobaric or hypobaric) leads to inhomogeneous HPV, resulting in an uneven perfusion of the lung with nonperfused areas next to hyperperfused areas [80]. The high capillary pressure in the latter may result in exudation, indicating the beginning of HAPE [11, 81, 82]. Chest X-rays and computerized axial tomography scans conducted in the early stages of HAPE show patchy pulmonary infiltrate, sometimes with peripheral predominance. With progression of HAPE these areas grow and merge to produce a homogeneous distribution [83], and bronchoalveolar lavage fluid contains exudate rich in proteins as well as erythrocytes as a sign of mild hemorrhage $[82,84]$.

Typical symptoms of HAPE are breathlessness, initially dry cough that eventually becomes productive with sputum turning from white to pink, tachycardia, and sometimes cyanosis [1, 7]. These symptoms develop in susceptible individuals within the first 2-4 days after arrival at altitudes above $2500 \mathrm{~m}$. The incidence depends on the ascent velocity and final altitude as well as individual susceptibility [7, 11]. Individuals at risk typically exhibit a marked rise in pulmonary arterial pressure (PAP) when exposed to hypoxia as a result of an exaggerated HPV [7], as well as a greater rise in PAP on exercise under normoxic conditions [7] and a reduced HVR compared with nonsusceptible controls [6, $85,86]$.

2.4. Treatment of Acute Complications. AMS is typically a self-limiting condition that will resolve after 3-4 days [87]. However, if symptoms persist, descent to a lower altitude is recommended. Furthermore, supplemental oxygen (2-4 L/min) will reduce the symptoms within $15-30 \mathrm{~min}$ [87, 88]. Besides prevention through slow ascent and inclusion of resting days between ascents $[89,90]$, AMS can also be prevented effectively by acetazolamide or dexamethasone [91-93], and these two medications are each recommended by the Wilderness Medical Society with an evidence level of 1A [91-94]. However, acetazolamide has to be started the day before the ascent and is thus unsuitable for people who need to make unplanned, excessively rapid ascents, for instance, emergency rescue personnel $[94,95]$. Dexamethasone should be considered first in such cases [96]. In 2014, Zheng et al. [97] showed that inhaled budesonide is able to prevent AMS to the same extent as oral dexamethasone [97]. As peak serum levels of budesonide are much lower than those of orally administered dexamethasone [98-100] the effect of budesonide is thought to be more focused on the lung tissue. The mechanisms underlying the effects of dexamethasone as well as inhaled budesonide are not fully understood, but dexamethasone is thought to increase the concentration of apical alveolar membrane $\mathrm{Na}^{+}$channels as well as basal $\mathrm{Na}^{+} \mathrm{K}^{+}$-ATPase [101], stimulate surfactant secretion [102], and prevent protein exudation [103].

The first line of defence against HACE lies in its prevention through adequate acclimatization by slow ascent [90]. Dexamethasone is a possible treatment option but, in contrast to acetazolamide, dexamethasone does not facilitate acclimatization and thus may lead to a false sense of security. Its real potential lies in its possible stabilizing effect as a rescue drug for patients with HACE prior to descent $[104,105]$.

HAPE may be prevented by slow ascent and allowing adequate time to acclimatize, as mentioned above [7]. In addition, there are several medical options for the reduction of HAPE incidents: the phosphodiesterase type 5 (PDE5) inhibitor tadalafil $(10 \mathrm{mg}$ twice daily [BID]) and dexamethasone (8 mg BID) have been well evaluated [106] as has slow-release nifedipine ( $30 \mathrm{mg}$ BID) [9]. When HAPE is evolving, the patient should descend to lower altitudes and receive immediate supplemental oxygen therapy $(2-4 \mathrm{~L} / \mathrm{min})$ if possible [7, 107]. In terms of pharmacological therapy, adjunctive treatment with nifedipine is the current standard, while the use of PDE5 inhibitors requires further evaluation [94].

In cases of HACE and HAPE where descent is not possible, alternative options are supplemental oxygen and a portable inflatable hyperbaric chamber that is able to increase 


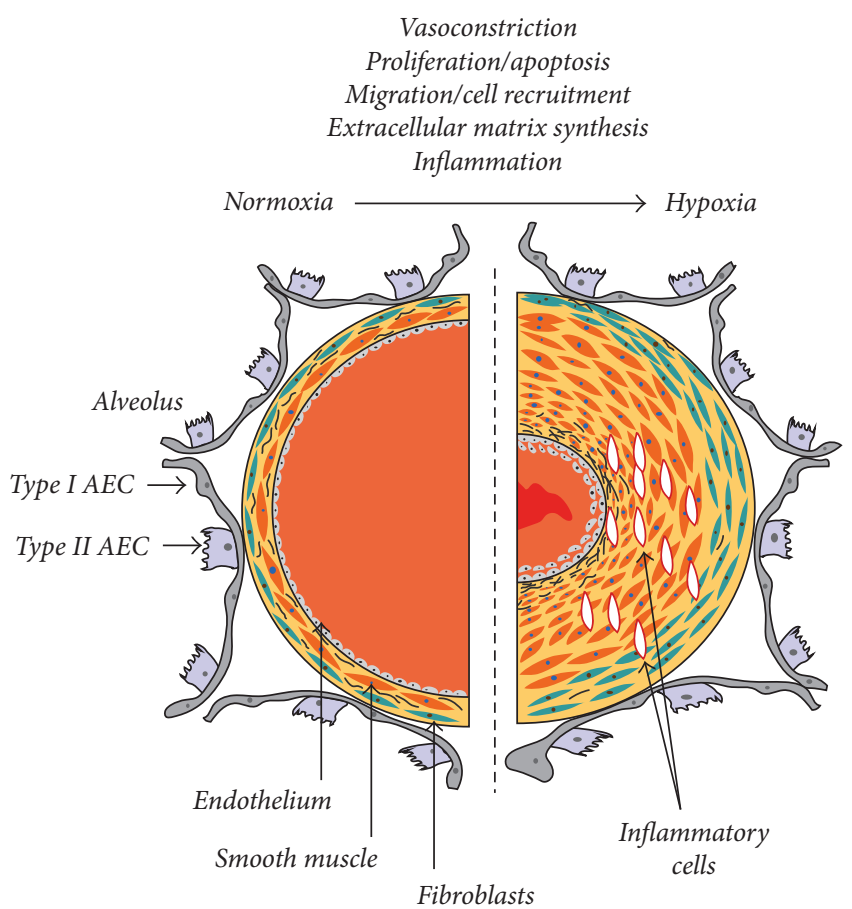

Cellular and molecular mechanisms

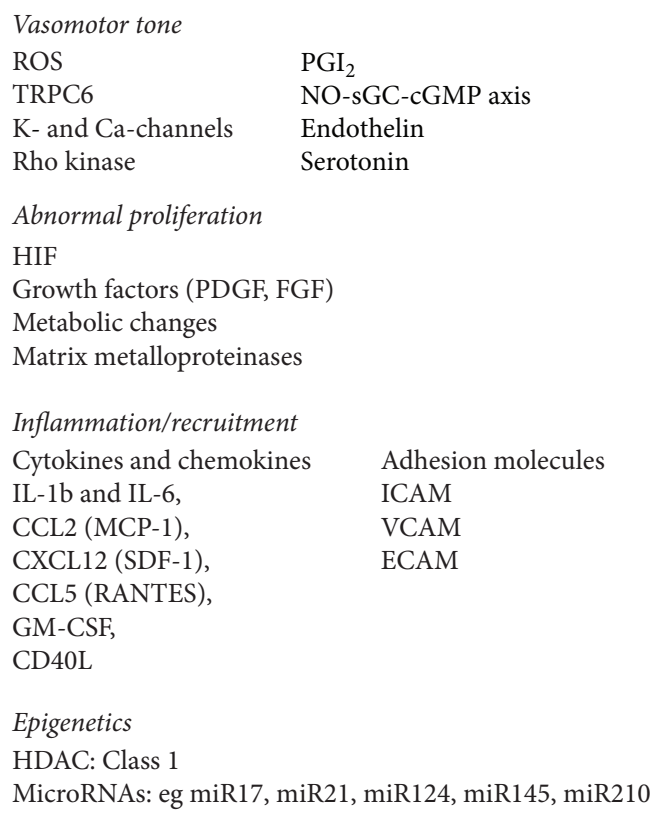

FIGURE 1: Mechanisms of vascular remodeling in chronic hypoxia (from [16], permission granted). AEC: alveolar epithelial cell; CCL: C-C motif chemokine ligand; CD40L: CD40 ligand; CXCL: C-X-C motif chemokine ligand; ECAM: endothelial cell adhesion molecule; FGF: fibroblast growth factor; HDAC: histone deacetylase; GM-CSF: granulocyte macrophage colony stimulating factor; HIF: hypoxia-inducible factor; ICAM: intercellular adhesion molecule; IL: interleukin; NO-sGC-cGMP: nitric oxide-soluble guanylate cyclase-cyclic GMP; MCP: monocyte chemoattractant protein; PDGF: platelet-derived growth factor; $\mathrm{PGI}_{2}$ : prostacyclin; RANTES: regulated upon activation, normally T-expressed, and presumably secreted; ROS: reactive oxygen species; SDF: stromal cell-derived factor; TRPC6: transient receptor potential cation channel 6; VCAM: vascular cell adhesion molecule.

air pressure to the level found at an altitude of approximately $1500 \mathrm{~m}[108,109]$.

\section{Long-Term Changes of the Cardiopulmonary System due to Hypoxia}

3.1. Hypoxia-Induced PH: Pathomechanisms and Preclinical Studies. Exposure to chronic hypoxia results in pulmonary vascular remodeling which is characterized by specific alterations of the large and small pulmonary vessels. These changes lead to $\mathrm{PH}$ and increased right ventricular (RV) afterload which can be further aggravated by increased blood viscosity [110]. Large pulmonary vessels show increased stiffening, while small pulmonary vessels exhibit thickening of the adventitial and medial layer and muscularization of formerly nonmuscularized precapillary vessels ("de novo" muscularization). Chronic hypoxia-induced vascular alterations are completely reversible after reexposure to normoxia.

On a cellular level, the remodeling of the small vessels is caused by increased proliferation and migration and decreased apoptosis of PASMC (Figure 1) [16], and the affected cells seem to comprise a specific subpopulation of PASMC that are not well differentiated. Additional alterations include increased proliferation and migration of fibroblasts that have the ability to differentiate into smooth muscle cell-like cells and secrete matrix proteins. It is possible that pericytes and circulating bone marrow cells also contribute to the pathogenesis of vascular remodeling; however, speciesspecific differences exist [111, 112]. Compared with human forms of pulmonary arterial hypertension and other nonhypoxia-induced forms of $\mathrm{PH}$, chronic hypoxia induces less alteration of the intima, specifically no formation of neointima and plexiform lesions [111]. However, alterations of endothelial cells also play a prominent role in chronic hypoxia-induced $\mathrm{PH}$, as they release increased levels of vasoconstrictive, proproliferative factors (e.g., endothelin [ET] 1, angiotensin II, VEGF, and platelet-derived growth factor[PDGF-] B) and reduced levels of vasodilatory, antiproliferative mediators (NO and prostaglandin $\mathrm{I}_{2}$ ), as well as increased amounts of adhesion molecules, cytokines, procoagulatory factors, and matrix proteins, which interact with adjacent cells and attract circulating immune and progenitor cell types $[112,113]$.

Hypoxia-induced endothelial stimuli and circulating systemic factors, as well as hypoxia per se, activate intracellular signaling cascades in PASMC involving tyrosine kinases, mitogen activated protein kinases, protein kinase C, phosphatidylinositol 3 kinase, SMAD phosphorylation, calcium inflow, and rho kinases, which all regulate cellular contractility, proliferation, and differentiation, as well as synthesis of matrix proteins. By contrast, antiproliferative signaling pathways which are regulated by cGMP or cyclic AMP become less active. Development of hypoxia-induced $\mathrm{PH}$ is further promoted by intrinsic genetic, epigenetic, 


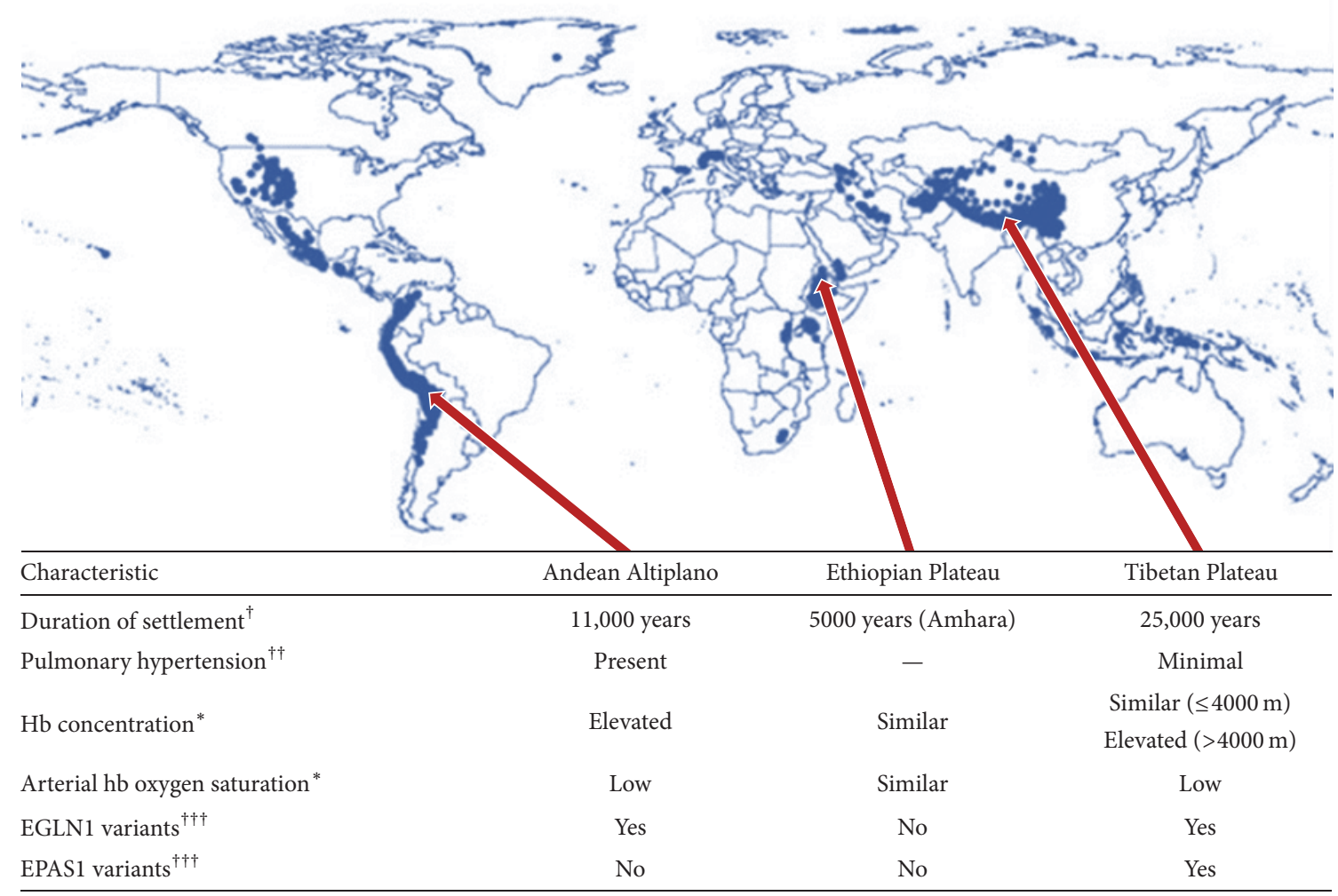

FIGURE 2: Map showing populated regions at altitudes of $2500 \mathrm{~m}$ or higher (from [17], permission granted), and characteristics of three major high-altitude populations. ${ }^{*}$ Compared with sea-level populations at low altitude (see $\left.[18,19]\right)$. EGLN1: hypoxia-inducible factor prolyl 4-hydroxylase 2; EPAS1: hypoxia-inducible factor-2 $\alpha$; hb: hemoglobin. $\dagger:[20,21], \uparrow \uparrow: ~[22-24], \uparrow \uparrow \uparrow: ~[25]$.

and acquired factors, such as bone morphogenetic protein receptor-2 mutations and hormones [112].

Many of these factors have been targeted with investigational therapies in animal models of chronic hypoxia-induced $\mathrm{PH}$, and beneficial effects have been shown. However, only a few targets have made the transition into clinical trials (for hypoxia-induced and/or other forms of $\mathrm{PH}$ ), such as the PDGF pathway which was addressed by tyrosine kinase inhibitors $[114,115]$ and the NO-cGMP pathway which was addressed by activators/stimulators of the soluble guanylate cyclase $[116,117]$. Further details of clinical studies in hypoxiainduced $\mathrm{PH}$ are provided in Section 3.3.

Mediators between the aforementioned intracellular signaling pathways and hypoxia, which may act as chronic hypoxic oxygen sensing mechanisms, include the activation of hypoxia-inducible factor (HIF) 1 , inhibition of mitochondria, and alterations in the release of ROS. HIF1 regulates transcription of proteins such as erythropoietin, VEGF, and ET1, as well as proteins that regulate cellular glycolytic and mitochondrial metabolism [118]. In accordance with the prominent role of HIF in hypoxia-induced $\mathrm{PH}$, mice with inducible PASMC-specific HIF1 $\alpha$ knock-out showed decreased development of PH [119]. The inhibition of mitochondrial metabolism and increased glycolytic ATP production (the so-called "metabolic switch") that has been observed in $\mathrm{PH}$ results in altered ROS release, antiapoptotic effects, activation of proliferative transcription factors, increased supply of components for protein synthesis, and altered cellular calcium homeostasis [120, 121]. Inhibition or reversal of mitochondrial alterations at several levels of interaction with the cellular signaling pathways could inhibit development of hypoxia-induced $\mathrm{PH}$ in mice and rats [121124]. ROS can interact with a plethora of redox-sensitive proliferative and antiapoptotic pathways and their role in conditions of chronic hypoxia is as controversial as their role in acute hypoxia. In this regard, both an increase [59, 125] and a decrease of ROS have been shown to stabilize HIF [126]. Animal studies suggest that ROS scavenging may be beneficial in chronic hypoxia-induced $\mathrm{PH}$ under certain circumstances [127-129].

3.2. Long-Term Adaptations in High-Altitude Populations. Studies of native high-altitude populations have also provided information regarding the mechanisms involved in (mal) adaptation to long-term hypobaric hypoxia. At varying times in history, humans colonized multiple high-altitude locales, including the Tibetan Plateau, the Andean Altiplano, and the Semien Plateau of Ethiopia [130]. The adaptation of these large populations to chronic hypoxia has been extensively studied (Figure 2). The Tibetan population has been a 
particular focus of research, because Tibetans are believed to have moved to the Tibetan Plateau (average elevation of $4000 \mathrm{~m}$ ) almost 25,000 years ago, which would have given them more time to adapt to chronic hypoxia than other highaltitude human populations such as the native inhabitants of the Andean Altiplano (settled 11,000 years ago) and the Amhara population in Ethiopia (settled 5000 years ago [20]).

3.2.1. Pulmonary Vascular System. Interestingly, high-altitude populations show relevant differences in their pulmonary vascular response to chronic hypoxia. Of note, Tibetans exhibit almost normal PAP, show minimal hypoxic $\mathrm{PH}$ [23], and lack the typical pathological findings of vascular remodeling [24]. By contrast, PH and CMS, including pathophysiological remodeling of the pulmonary arteries, are evident among Andeans [22]. These differences are most probably the result of the Tibetan population living above $3000 \mathrm{~m}$ for thousands of years longer than the Andean population.

In general, it is believed that increases in hematocrit and hemoglobin (hb) concentration negatively influence pulmonary pressures and resistance [131]. In this context, it is noteworthy that Tibetan highlanders have significantly lower hb concentrations than Andean highlanders or Han Chinese migrants to high altitude [132]. Highlanders undergoing right heart catheterization while being physically challenged were also found to have reduced pulmonary vascular distensibility with impaired and inadequate response of the $\mathrm{CO}$ to exercise $[133,134]$. However, subsequent studies of highlanders showed a wide range of responses of the pulmonary vascular system to exercise $[135,136]$. Overall, results indicate that pulmonary vascular distensibility and $\mathrm{CO}$ response are impaired in highlanders, with individual and ethnic variability.

Interestingly, manifest hypoxic $\mathrm{PH}$ in highlanders is almost reversible after two years of low-altitude exposure [137]. Substantial alterations in the release of vasodilatory factors, especially NO, are believed to contribute to the highaltitude phenotypes. Compared with lowland inhabitants, Tibetan highlanders exhibit higher levels of circulating NO [138], as well as a higher NO transfer rate within the pulmonary circulation (implying an enhanced pulmonary vasodilatation) [139].

3.2.2. Genomic Studies. The local variability in the response to chronic hypoxia raised the question whether different genes might have been influenced by natural selection in the three major high-altitude populations. The HIF system has been described as the major genetic pathway [132], and HIF is believed to control hundreds of genes in response to cellular hypoxia.

In Tibetan highlanders, variants in several major HIF upstream genes such as EPAS1 (HIF-2 $\alpha$ ) and EGLN1 (HIF prolyl 4-hydroxylase 2) have been identified. It is believed that these variants contribute to the low hb concentrations in Tibetans $[25,140,141]$. In particular, a missense mutation in EGLN1 prevents hypoxia-induced and HIF-mediated enhancement of erythropoiesis [142]. Moreover, HMOX2 (heme oxygenase 2; downstream of HIF) has recently been identified as a relevant modifier of hb metabolism and contributor to high-altitude adaptation in Tibetan highlanders [143]. In addition, variants of the major upstream transcriptional regulator EPAS1 were also significantly associated with low hb concentrations in Tibetan highlanders [144]. The low hb concentration and concomitant reduction of blood viscosity compared with acclimatized lowlanders might be an important mechanism to maintain cardiopulmonary circulation in Tibetan highlanders [16].

Genome-wide studies of Andean highlanders showed an overlap with Tibetan highlanders for variation in EGLN1 but not EPAS1 [25]. Nevertheless, no relevant association between EGLN1 genotype and hb levels was evident in Andean highlanders. In addition, variants in EGLN1 and EPAS1 did not significantly contribute to Ethiopian hb concentrations [20]. However, high-altitude adaptation in Ethiopian highlanders is believed to be regulated via several different genes involved in vascular physiology such as $\mathrm{CXC17}$ (CXC chemokine 17) and PAFAH1B3 (platelet activating factor acetylhydrolase $1 \mathrm{~b}$ catalytic subunit 3) [145, 146]. Although the large highland populations have developed different genetic variants, some major pathways show a relevant overlap. Many other variants in major genetic pathways have been discovered, but these genetic variants alone might not be sufficient to explain fully the adaptation to chronic hypoxia. It is possible that other pathways will be discovered from studies in larger cohorts.

3.3. Clinical Studies. An overview of clinical studies of potential treatments for high altitude $\mathrm{PH}$ is presented in Table 2. The 2005 consensus statement on high altitude $\mathrm{PH}$ included results from two studies [8]. The effect of nifedipine was assessed in a case-control study that included 31 patients with high altitude $\mathrm{PH}$ diagnosed and treated in Bolivia at an altitude of $3600 \mathrm{~m}$ [44]. A 20\% decrease in pulmonary arterial systolic pressure (PASP) was noted in two-thirds of the patients (classed as responders). In terms of limitations, it should be noted that the study was based on echocardiography only. In addition, although CO increased to a greater extent in responders than in nonresponders, heart rate and systemic systolic blood pressure did not show responses consistent with the pulmonary vascular response (heart rate increased to a similar extent in responders and nonresponders, and systemic systolic blood pressure showed a greater decrease in nonresponders than in responders) [44]. In another study in Bolivia (also at an altitude of $3600 \mathrm{~m}$ ), the effect of isovolemic hemodilution was assessed in eight native residents [45]. Three of the eight participants had high altitude $\mathrm{PH}$. Isovolemic hemodilution led to an increase in $\mathrm{CO}$ in all three participants with $\mathrm{PH}$ but had no consistent effect on mean PAP. Based on the data available at the time, the 2005 consensus statement recommended migration to low altitude as the ideal treatment for high altitude $\mathrm{PH}$ and noted that there was an urgent need for randomized controlled trials of possible alternatives such as calciumchannel blockers, ET receptor antagonists, prostaglandins, and PDE5 inhibitors [8].

In 2005, a randomized controlled trial of the PDE5 inhibitor sildenafil in 22 patients with high altitude $\mathrm{PH}$ in 


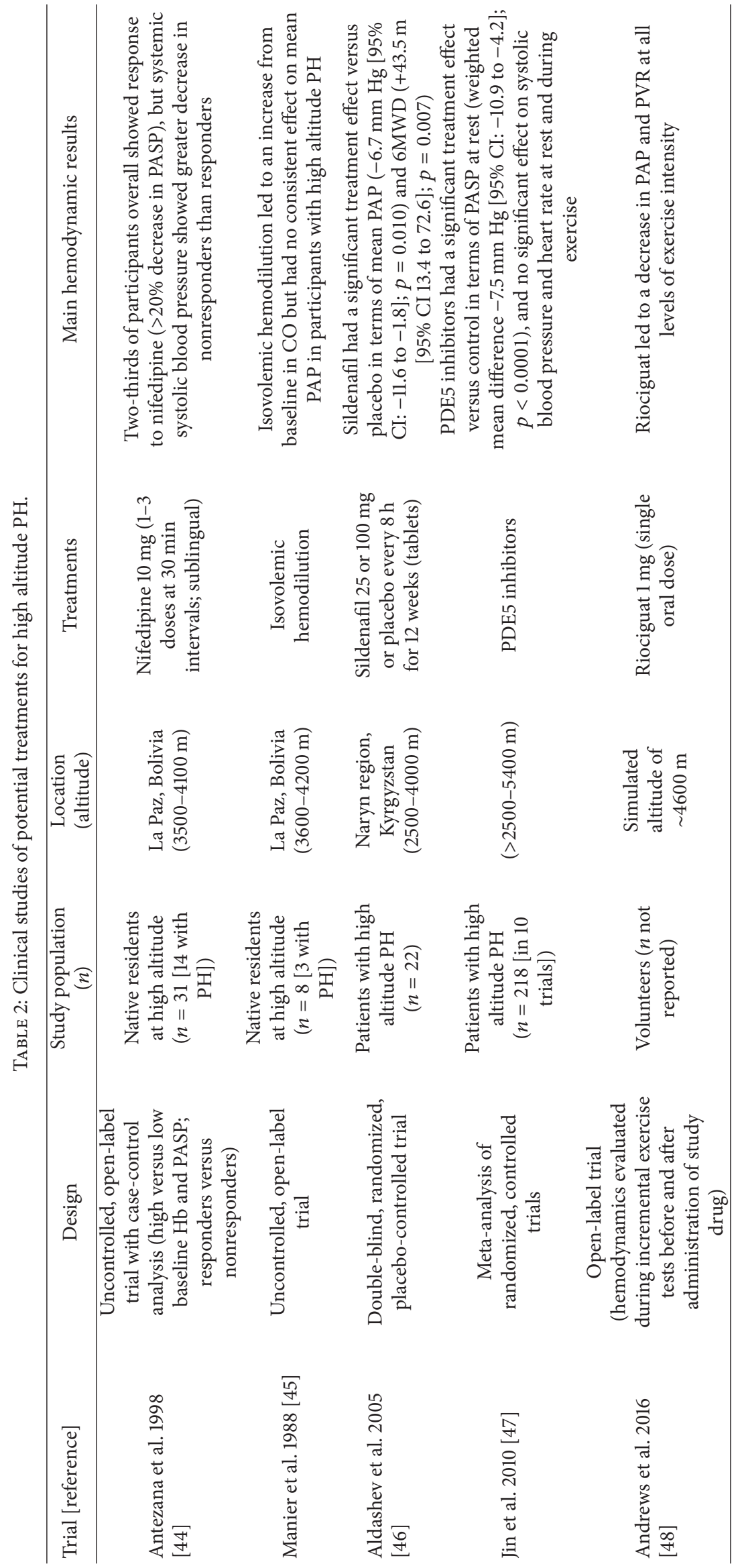




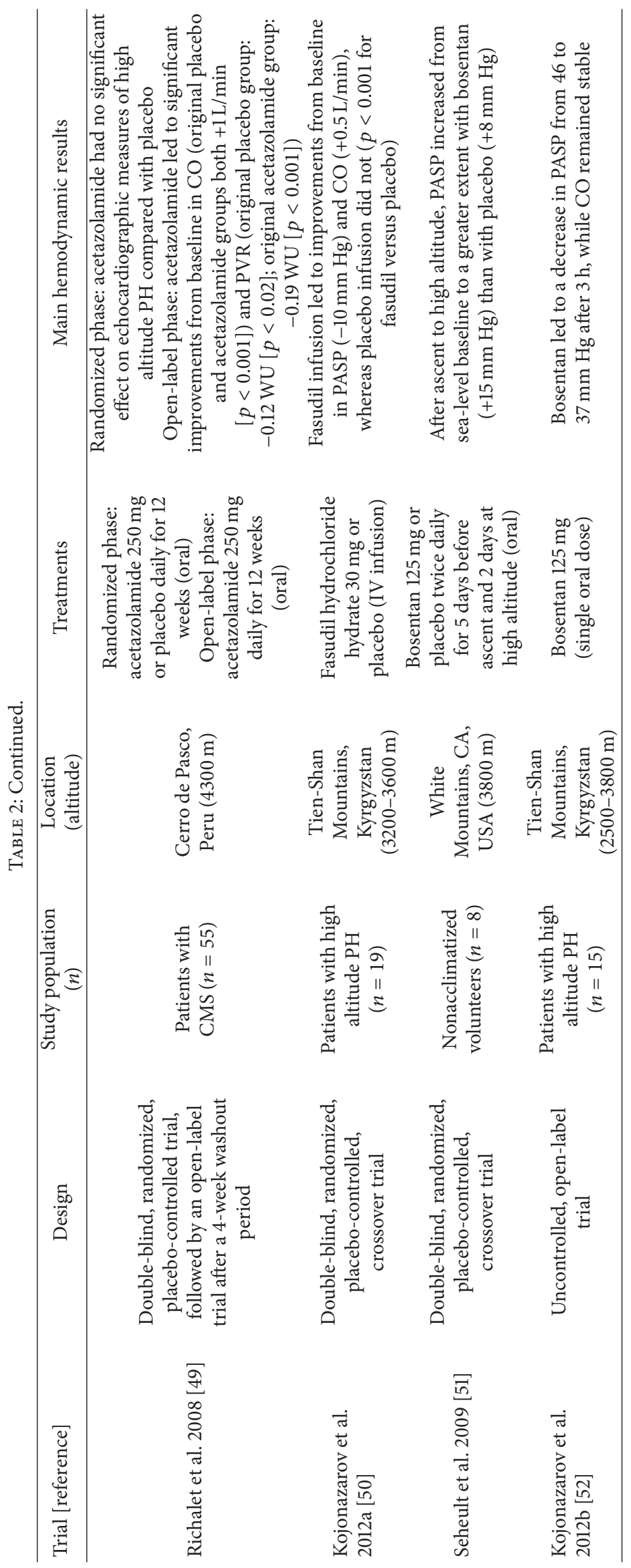




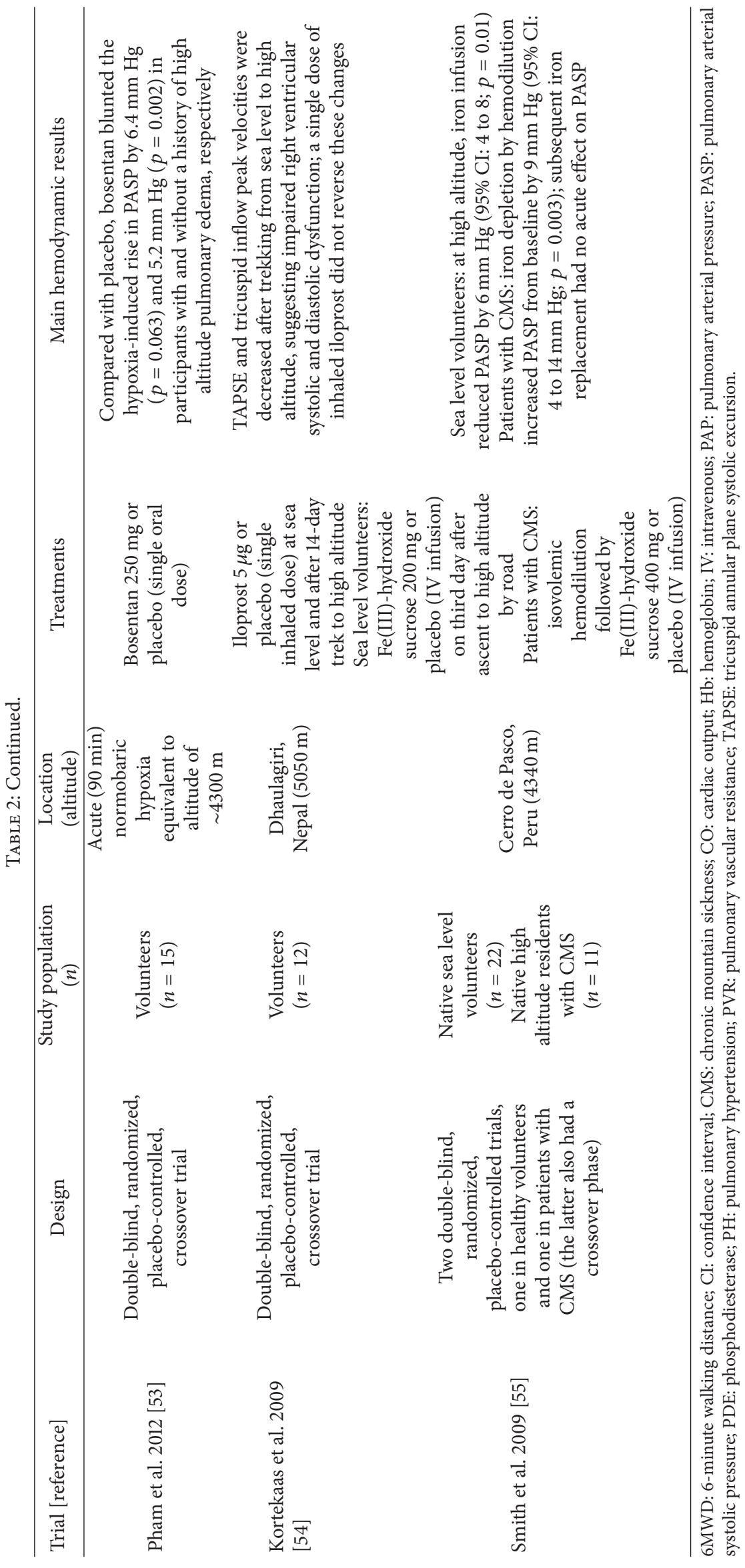


Kyrgyzstan was published [46]. The patients were randomly assigned to receive sildenafil $25 \mathrm{mg}$ or $100 \mathrm{mg}$ three times daily or placebo. Right heart catheterization was carried out at baseline and after 12 weeks of treatment. The patients receiving active treatment had a significantly greater reduction in PAP $(-6 \mathrm{~mm} \mathrm{Hg})$ than those receiving placebo $(+1 \mathrm{~mm} \mathrm{Hg})$. Changes in pulmonary vascular resistance and $\mathrm{CO}$ showed no difference between the sildenafil and placebo groups, but the higher dose of sildenafil increased $\mathrm{CO}$ and decreased pulmonary vascular resistance much more than the lower dose. The placebo-corrected increase in six-minute walking distance was more than $40 \mathrm{~m}$ for both sildenafil doses [46]. A 2010 meta-analysis of ten trials came to the conclusion that PDE5 inhibitors reduce PASP and have beneficial effects in patients with high altitude $\mathrm{PH}$ [47]. The NO-cGMP pathway has also been targeted by the soluble guanylate cyclase stimulator riociguat, which reduced PAP and pulmonary vascular resistance in volunteers during exercise at a simulated altitude of $\sim 4600 \mathrm{~m}$ [48].

Measures of high altitude $\mathrm{PH}$ were followed as secondary endpoints in a study of acetazolamide in 55 patients with CMS in Peru [49]. After a double-blind, randomized, placebo-controlled phase, all patients received openlabel acetazolamide. The increased hematocrit improved significantly with acetazolamide compared with placebo. No echocardiographic measures of high altitude $\mathrm{PH}$ improved with acetazolamide compared with placebo. However, CO improved significantly from baseline in the open-label phase $(+1 \mathrm{~L} / \mathrm{min})$. The patients treated in this study most likely had no $\mathrm{PH}$ at baseline (echocardiographic PASP: $34 \mathrm{~mm} \mathrm{Hg}$ plus right atrial pressure) [49].

The rho kinase inhibitor fasudil showed impressive effects in an acute hemodynamic study in 19 Kyrgyz patients living at altitudes above $3200 \mathrm{~m}$ with high altitude $\mathrm{PH}$ [50]. The placebo-controlled cross-over design allowed two acute echocardiographic evaluations of the right heart before and after infusion of fasudil ( $1 \mathrm{mg} / \mathrm{min}$ ) or placebo over $30 \mathrm{~min}$. Following fasudil infusion, PASP decreased by $10 \mathrm{~mm} \mathrm{Hg}$ from a baseline of $52 \mathrm{~mm} \mathrm{Hg}$ and CO increased by $0.5 \mathrm{~L} / \mathrm{min}$ from a baseline of $6.1 \mathrm{~L} / \mathrm{min}$; neither parameter showed any change from baseline following placebo infusion [50].

Bosentan, an ET receptor antagonist approved for the treatment of pulmonary arterial hypertension, was tested as prophylaxis in healthy volunteers (maximal oxygen uptake: $52 \mathrm{~mL} / \mathrm{kg} \cdot \mathrm{min}$ ) taken by motor vehicle to an altitude of $3800 \mathrm{~m}$ for evaluation of echocardiographic parameters and exercise capacity [51]. Compared with placebo, bosentan was associated with a greater increase from sea-level baseline in PASP ( $+15 \mathrm{~mm} \mathrm{Hg}$ [bosentan] versus $+8 \mathrm{~mm} \mathrm{Hg}$ [placebo]) and lower oxygen saturation during exercise (78\% versus $85 \%)$. Other relevant measures did not differ [51]. However, an acute hemodynamic study showed a beneficial effect of bosentan on PASP (measured by echocardiography) in 15 Kyrgyz patients with invasively proven high altitude $\mathrm{PH}$ : a single oral dose of bosentan led to a decrease in PASP from 46 to $37 \mathrm{~mm} \mathrm{Hg}$ after $3 \mathrm{~h}$, while $\mathrm{CO}$ and pulsoxymetric saturation remained stable [52]. Another echocardiography study in healthy volunteers showed that a single dose of bosentan blunted the rise in PASP caused by acute (90 min) hypoxia exposure [53].

The effect of inhaled iloprost, a prostanoid therapy approved for the treatment of pulmonary arterial hypertension, was assessed in an echocardiography study of 12 healthy volunteers at an altitude of $5050 \mathrm{~m}$. The results suggested that a prolonged stay at high altitude led to impairment of RV systolic and diastolic function which was not reversed by inhalation of a single dose of iloprost (5 $\mu \mathrm{g})$ [54].

The effect of iron depletion or supplementation on PASP was evaluated in two randomized, controlled, echocardiography studies, albeit not in patients with high altitude $\mathrm{PH}$ : one study assessed healthy volunteers ascending to $4340 \mathrm{~m}$ and the other study enrolled patients with CMS and PASP within the normal range (mean: $37 \mathrm{~mm} \mathrm{Hg}$ ) [55]. The estimated increase in PASP in healthy volunteers after ascent was partly reversed by iron supplementation (reduction by $6 \mathrm{~mm} \mathrm{Hg}$ ), but never reached pathological levels. In patients with CMS, progressive iron deficiency (induced by venesection and isovolemic donation of $2 \mathrm{~L}$ of blood) increased the estimated PASP by $9 \mathrm{~mm} \mathrm{Hg}$. Subsequent iron replacement did not change the PASP [55].

3.3.1. (Possible) Treatment Options. As for other conditions at high altitude, descent is life saving for severe cases [16]. However, if descent is not possible, pharmacologic treatment can be considered. PDE5 inhibitors have the broadest evidence base to date, and high doses (e.g., $100 \mathrm{mg}$ three times daily) of sildenafil could be considered. Further studies of pharmacologic treatments for high altitude $\mathrm{PH}$ are needed.

\section{The Right Ventricle in Hypoxia}

In hypoxic conditions such as in high altitude, right sided heart failure due to HPV and pulmonary vascular remodeling with the resulting increase in afterload is one of the most feared life-threatening diseases. Only $1 \%$ of previously healthy individuals with pulmonary vascular hyperreactivity to hypoxia and severe hypoxic $\mathrm{PH}$ are at risk of developing right heart failure in high altitude [131, 147]. The incidence of right heart failure in hypoxic conditions, for instance, at high altitude, is by no means proportional to high pulmonary pressure. It remains to be elucidated why some high-altitude residents with high PAP are able to live "normal" lives with no restrictions in their activities [148], whereas others develop right heart failure.

\subsection{How Does the Right Ventricle React to Hypoxic Conditions?} The most illuminating studies in this context are those conducted at high altitude or in conditions similar to the hypoxic conditions of high altitude. Huez et al. [149] exposed 25 healthy volunteers to hypoxia for $90 \mathrm{~min}$ (fraction of inspired $\mathrm{O}_{2}: 0.12$ ) or dobutamine (titrated to produce the same effect on heart rate without changing pulmonary vascular tone) and explored the effects on RV and left ventricular function using standard Doppler echocardiography, pulsed tissue Doppler imaging, and longitudinal systolic strain and strain-rate imaging. Hypoxia and dobutamine both increased $\mathrm{CO}$ and correspondingly tricuspid regurgitation velocity as 
an index for PAP. Conventional echocardiography and tissue Doppler imaging revealed that dobutamine increased RV indices of systolic function (such as RV area shortening fraction, tricuspid annular plane systolic excursion [TAPSE], or systolic ejection wave velocity $[S]$ at the tricuspid annulus), whereas hypoxia did not. Accordingly, longitudinal wall motion analysis revealed that $S$, systolic strain, and strain rate on the RV free wall and interventricular septum were increased by dobutamine but were not affected by hypoxia. These results indicate that systolic function of the right ventricle is not altered in hypoxia. Instead, early diastolic function appears to be affected; tissue Doppler imaging revealed that hypoxia increased the isovolumic relaxation time relative to the RR interval and delayed the onset of the $E$ wave at the tricuspid annulus.

Echocardiographic measurements were performed by the same group [150] in 15 healthy lowlanders at different altitudes (sea level; $<24 \mathrm{~h}$ after arrival in La Paz, Bolivia, at $3750 \mathrm{~m}$; and after 10 days of acclimatization and ascent to Huayna Potosi, at $4850 \mathrm{~m}$ ), and the results were compared with those obtained in 15 age- and body size-matched inhabitants of Oruro, Bolivia, at $4000 \mathrm{~m}$. Acute exposure to high altitude in lowlanders caused an increase in mean PAP to $20-25 \mathrm{~mm} \mathrm{Hg}$, altered RV diastolic function (indicated by a decreased $E / A$ ratio as well as a prolonged isovolumic relaxation time contributing to an increased RV Tei index), and maintained RV systolic function (measured by TAPSE and $S$ at the tricuspid annulus). Compared with the lowlanders exposed to high altitude, the native highlanders had lower PAP but greater alteration in diastolic function, decreased TAPSE and $S$ at the tricuspid annulus, and an increased RV Tei index. The cardiac adaptations to high altitude appeared qualitatively similar between both groups, but with significant deterioration of indices of systolic and diastolic function in high-altitude dwellers. According to the authors, these results could be an effect of a lesser degree of sympathetic nervous system activation in the native highlanders.

Allemann and colleagues [151] assessed the effects of rapid ascent to high altitude on PAP and right and left ventricular function by echocardiography in 118 nonacclimatized healthy children and adolescents. The echocardiography was performed at low altitude and $40 \mathrm{~h}$ after rapid ascent to $3450 \mathrm{~m}$. PAP, estimated by measuring the systolic RV to right atrial pressure gradient, was significantly higher at high altitude than at low altitude. There was no depression in RV systolic function even in children with the most severe altitude-induced PH. RV systolic function even increased in the latter group. Naeije and colleague discussed another possible mechanism of right heart failure. Chronic hypoxia and relative hypercapnia could be a cause of salt and water retention in the mildly afterloaded right heart. This would lead to congestion, but remains to be proven in large studies [131].

Recently Crnkovic and colleagues [152] used a mouse model of chronic hypoxia to describe RV function in hypoxia. In this model, TAPSE was significantly decreased in hypoxia, whereas invasive measurements demonstrated a significantly increased maximal rate of rise in RV pressure
( $\mathrm{RV} \max \mathrm{dP} / \mathrm{dt}$ ) and an unchanged $\mathrm{RV}$ contractility index. The authors concluded that RV systolic function is maintained in hypoxia, despite the decreased TAPSE. Due to its pressure-dependency, $\mathrm{dP} / \mathrm{dt}$ [153] is a very vague parameter to describe RV contractility and therefore we need studies (in humans as well as animals) that investigate RV contractility and RV-arterial coupling using the accepted parameters Ees/Ea (ventricular end-systolic elastance/arterial elastance), in order to be able to measure the "correct" systolic function.

Recently Stembridge et al. [154] performed twodimensional, Doppler, and speckle-tracking echocardiography on adolescent highland Sherpa (altitude: $3840 \mathrm{~m}$; $n=26)$ compared with age-matched lowland Sherpa (altitude: $1400 \mathrm{~m} ; n=10$ ) and lowland Caucasian controls (sea level; $n=30$ ). The RV diastolic area showed no significant difference between the groups, whereas RV longitudinal strain and strain rate (reflecting contractile function) were lower in highland Sherpa compared with lowland Sherpa, with no difference between highland Sherpa and lowland Caucasian controls.

In conclusion, most of the studies investigating $\mathrm{RV}$ function in hypoxia are small and the majority of them used echocardiographic measurements to assess diastolic or systolic RV function. Further investigations should be done in order to assess the load-independent (as far as systolic function is concerned) parameter Ees and its relationship to Ea. All the other parameters mentioned above are indirect parameters, which at least give us some evidence that the systolic function of the right ventricle in most studies is not impaired, whereas the diastolic function is slightly reduced due to the increasing afterload. Investigations of Ees/Ea would enable us to measure directly the contractility of the right ventricle, providing us with more information about the reaction of the right ventricle to hypoxia.

\section{Summary}

Acute responses to hypobaric hypoxia include increased heart rate, increased erythrocyte concentration, increased breathing frequency and tidal volume (HVR), and HPV leading to increased pulmonary vascular resistance and right ventricular afterload. Acute maladaptation results in increased CNS perfusion and intracellular fluid accumulation (AMS, which can lead to potentially fatal HACE), as well as inhomogeneous HPV leading to hyperperfusion of some areas of the lung with subsequent exudation (HAPE). Acute maladaptation may be prevented by slow ascent and/or by administration of acetazolamide or dexamethasone; tadalafil and nifedipine are also options for reduction of HAPE events. Treatment of acute maladaptation involves descent to a lower altitude and/or administration of supplemental oxygen; dexamethasone may be used to stabilize patients with HACE prior to descent, and nifedipine is used as adjunctive therapy in HAPE.

Chronic hypoxia leads to pulmonary vascular remodeling (and thus PH) via HIFl activation, mitochondrial inhibition, altered ROS release, and downstream alteration of many signaling pathways in endothelial cells and PASMC. The 
resulting increase in RV afterload can lead to the development of life-threatening right heart failure. Despite extensive study of physiological adaptations in native high-altitude populations and the evaluation of multiple potential pharmacological targets in animal models, few pharmacological treatments for hypoxia-induced $\mathrm{PH}$ have entered clinical trials. PDE5 inhibitors have the most evidence to date, and further studies of pharmacological therapies are needed. Data on RV function in hypoxia are also limited, and future studies should assess RV contractility directly by investigating Ees and Ea.

\section{Conflicts of Interest}

Jan Grimminger has received financial research support by Actelion, speaker fees by MSD, and support for participation in education/congresses by Actelion and Bayer Pharma AG. Manuel Richter has received support from United Therapeutics and Bayer Pharma AG and speaker fees from Actelion, Mundipharma, Roche, and United Therapeutics. Natascha Sommer has declared no conflicts of interest. Henning Gall received honoraria for talks and/or consultancy and financial support for participation in education/congresses and/or clinical research from Actelion, AstraZeneca, Bayer, BMS, GSK, Janssen Cilag, Lilly, MSD, Novartis, OMT, Pfizer, and United Therapeutics. Khodr Tello has declared no conflicts of interest. Hossein Ardeschir Ghofrani received honoraria for talks and/or consultancy and financial support for participation in education/congresses and/or clinical research from Actelion, AstraZeneca, Bayer, GSK, Janssen Cilag, Lilly, MSD, Novartis, OMT, Pfizer, and United Therapeutics.

\section{Authors' Contributions}

Jan Grimminger and Manuel Richter contributed equally to this work.

\section{Acknowledgments}

The authors thank Claire Mulligan, Ph.D. (Beacon Medical Communications Ltd, Brighton, UK) for editorial support, funded by the University of Giessen.

\section{References}

[1] J. B. West, "High-altitude medicine," American Journal of Respiratory and Critical Care Medicine, vol. 186, no. 12, pp. 12291237, 2012.

[2] C. Bouchard, F. T. Dionne, J. A. Simoneau, and M. R. Boulay, "Genetics of aerobic and anaerobic performances," Exercise and Sport Sciences Reviews, vol. 20, pp. 27-58, 1992.

[3] J. B. West, P. H. Hackett, K. H. Maret et al., "Pulmonary gas exchange on the summit of Mount Everest," Journal of Applied Physiology: Respiratory, Environmental and Exercise Physiology, vol. 55 , no. 3, pp. 678-687, 1983.

[4] J. A. L. Calbet and C. Lundby, "Air to muscle O2 delivery during exercise at altitude," High Altitude Medicine and Biology, vol. 10, no. 2, pp. 123-134, 2009.

[5] M. Mizuno, G. K. Savard, N.-H. Areskog, C. Lundby, and B. Saltin, "Skeletal muscle adaptations to prolonged exposure to extreme altitude: a role of physical activity?" High Altitude Medicine and Biology, vol. 9, no. 4, pp. 311-317, 2008.

[6] P. Bartsch and D. M. Bailey, "Acute mountain sickness and high altitude cerebral oedema," in High Altitude Human Adaptation to Hypoxia, E. R. Swenson and P. Bartsch, Eds., pp. 379-403, Springer, New York, NY, USA, 2014.

[7] P. Bärtsch and E. R. Swenson, "Clinical practice: acute highaltitude illnesses," New England Journal of Medicine, vol. 368, no. 24, pp. 2294-2302, 2013.

[8] F. León-Velarde, M. Maggiorini, J. T. Reeves et al., "Consensus statement on chronic and subacute high altitude diseases," High Altitude Medicine and Biology, vol. 6, no. 2, pp. 147-157, 2005.

[9] P. Bärtsch, M. Maggiorini, M. Ritter, C. Noti, P. Vock, and O. Oelz, "Prevention of high-altitude pulmonary edema by nifedipine," The New England Journal of Medicine, vol. 325, no. 18, pp. 1284-1289, 1991.

[10] M. W. Eldridge, A. Podolsky, R. S. Richardson et al., "Pulmonary hemodynamic response to exercise in subjects with prior highaltitude pulmonary edema," Journal of Applied Physiology, vol. 81, no. 2, pp. 911-921, 1996.

[11] M. Maggiorini, C. Mélot, S. Pierre et al., "High-altitude pulmonary edema is initially caused by an increase in capillary pressure," Circulation, vol. 103, no. 16, pp. 2078-2083, 2001.

[12] P. Bärtsch, D. M. Bailey, M. M. Berger, M. Knauth, and R. W. Baumgartner, "Acute mountain sickness: controversies and advances," High Altitude Medicine and Biology, vol. 5, no. 2, pp. 110-124, 2004.

[13] P. W. Barry and A. J. Pollard, "Altitude illness," British Medical Journal, vol. 326, no. 7395, pp. 915-919, 2003.

[14] D. Martin and J. Windsor, "From mountain to bedside: understanding the clinical relevance of human acclimatisation to high-altitude hypoxia," Postgraduate Medical Journal, vol. 84, no. 998 , pp. 622-627, 2008.

[15] M. A. Pasha and J. H. Newman, "High-altitude disorders: pulmonary hypertension: pulmonary vascular disease: the global perspective," Chest, vol. 137, no. 6, supplement, pp. 13S-19S, 2010.

[16] M. R. Wilkins, H.-A. Ghofrani, N. Weissmann, A. Aldashev, and L. Zhao, "Pathophysiology and treatment of high-altitude pulmonary vascular disease," Circulation, vol. 131, no. 6, pp. 582590, 2015.

[17] C. M. Beall, "Human evolution at high altitude," in High Altitude: Human Adaptation to Hypoxia, R. E. Swenson and P. Bärtsch, Eds., pp. 357-377, Springer, New York, NY, USA, 2014.

[18] C. M. Beall, "Andean, Tibetan, and Ethiopian patterns of adaptation to high-altitude hypoxia," Integrative and Comparative Biology, vol. 46, no. 1, pp. 18-24, 2006.

[19] C. M. Beall, M. J. Decker, G. M. Brittenham, I. Kushner, A. Gebremedhin, and K. P. Strohl, "An ethiopian pattern of human adaptation to high-altitude hypoxia," Proceedings of the National Academy of Sciences of the United States of America, vol. 99, no. 26, pp. 17215-17218, 2002.

[20] G. Alkorta-Aranburu, C. M. Beall, D. B. Witonsky, A. Gebremedhin, J. K. Pritchard, and A. Di Rienzo, "The genetic architecture of adaptations to high altitude in Ethiopia," PLoS Genetics, vol. 8, no. 12, Article ID e1003110, 2012.

[21] M. S. Aldenderfer, "Moving up in the world," American Scientist, vol. 91, no. 6, pp. 542-549, 2003.

[22] L. G. Moore, F. V. Armaza, M. Villena, and E. Vargas, "Comparative aspects of high-altitude adaptation in human populations," Advances in Experimental Medicine and Biology, vol. 475, pp. 45-62, 2000. 
[23] B. M. Groves, T. Droma, J. R. Sutton et al., "Minimal hypoxic pulmonary hypertension in normal Tibetans at 3,658 m," Journal of Applied Physiology, vol. 74, no. 1, pp. 312-318, 1993.

[24] M. L. Gupta, K. S. Rao, I. S. Anand, A. K. Banerjee, and M. S. Boparai, "Lack of smooth muscle in the small pulmonary arteries of the native Ladakhi: is the Himalayan highlander adapted?" American Review of Respiratory Disease, vol. 145, no. 5, pp. 1201-1204, 1992.

[25] A. W. Bigham and F. S. Lee, "Human high-altitude adaptation: forward genetics meets the HIF pathway," Genes and Development, vol. 28, no. 20, pp. 2189-2204, 2014.

[26] R. Naeije, C. Melot, P. Mols, and R. Hallemans, "Effects of vasodilators on hypoxic pulmonary vasoconstriction in normal man," Chest, vol. 82, no. 4, pp. 404-410, 1982.

[27] K. Klausen, "Cardiac output in man in rest and work during and after acclimatization to 3,800 m," Journal of Applied Physiology, vol. 21, no. 2, pp. 609-616, 1966.

[28] J. A. Vogel and C. W. Harris, "Cardiopulmonary responses of resting man during early exposure to high altitude," Journal of Applied Physiology, vol. 22, no. 6, pp. 1124-1128, 1967.

[29] S. R. Hopkins, H. J. Bogaard, K. Niizeki, Y. Yamaya, M. G. Ziegler, and P. D. Wagner, " $\beta$-adrenergic or parasympathetic inhibition, heart rate and cardic output during normoxic and acute hypoxic exercise in humans," Journal of Physiology, vol. 550, no. 2, pp. 605-616, 2003.

[30] R. S. Mazzeo, P. R. Bender, G. A. Brooks et al., "Arterial catecholamine responses during exercise with acute and chronic high-altitude exposure," American Journal of Physiology, vol. 261, no. 4, pp. E419-E424, 1991.

[31] J. B. West, "The physiologic basis of high-altitude diseases," Annals of Internal Medicine, vol. 141, no. 10, pp. 789-800, 2004.

[32] J. V. Weil, E. Byrne-Quinn, I. E. Sodal, G. F. Filley, and R. F. Grover, "Acquired attenuation of chemoreceptor function in chronically hypoxic man at high altitude," The Journal of Clinical Investigation, vol. 50, no. 1, pp. 186-195, 1971.

[33] M. Tannheimer, C. Fusch, D. Böning, A. Thomas, M. Engelhardt, and R. Schmidt, "Changes of hematocrit and hemoglobin concentration in the cold himalayan environment in dependence on total body fluid," Sleep and Breathing, vol. 14, no. 3, pp. 193-199, 2010.

[34] J. E. Greenleaf, H. Hinghofer-Szalkay, A. Rössler et al., "Plasma sodium-osmotic dissociation and hormonal interaction with drinking-induced hypervolemia at $2800 \mathrm{~m}$ altitude," Aviation Space and Environmental Medicine, vol. 72, no. 6, pp. 522-528, 2001.

[35] A. Honig, "Peripheral arterial chemoreceptors and reflex control of sodium and water homeostasis," American Journal of Physiology, vol. 257, no. 6, part 2, pp. R1282-R1302, 1989.

[36] M. N. Sawka, A. J. Young, P. B. Rock et al., "Altitude acclimatization and blood volume: effects of exogenous erythrocyte volume expansion," Journal of Applied Physiology, vol. 81, no. 2, pp. 636642, 1996.

[37] M. Basu, A. S. Malhotra, K. Pal et al., "Erythropoietin levels in lowlanders and high-altitude natives at $3450 \mathrm{~m}$," Aviation Space and Environmental Medicine, vol. 78, no. 10, pp. 963-967, 2007.

[38] N. Weissmann, F. Grimminger, D. Walmrath, and W. Seeger, "Hypoxic vasoconstriction in buffer-perfused rabbit lungs," Respiration Physiology, vol. 100, no. 2, pp. 159-169, 1995.

[39] N. Sommer, A. Dietrich, R. T. Schermuly et al., "Regulation of hypoxic pulmonary vasoconstriction: basic mechanisms," European Respiratory Journal, vol. 32, no. 6, pp. 1639-1651, 2008.
[40] U. S. Von Euler and G. Liljestrand, "Observations on the pulmonary arterial blood pressure in the cat," Acta Physiologica Scandinavica, vol. 12, no. 4, pp. 301-320, 1946.

[41] N. C. Staub, "Site of hypoxic pulmonary vasoconstriction," Chest, vol. 88, no. 4, pp. 240S-245S, 1985.

[42] P. I. Aaronson, T. P. Robertson, and J. P. T. Ward, "Endotheliumderived mediators and hypoxic pulmonary vasoconstriction," Respiratory Physiology and Neurobiology, vol. 132, no. 1, pp. 107120, 2002.

[43] E. D. Robin, J. Theodore, C. M. Burke et al., "Hypoxic pulmonary vasoconstriction persists in the human transplanted lung," Clinical Science, vol. 72, no. 3, pp. 283-287, 1987.

[44] A. M. Antezana, G. Antezana, O. Aparicio, I. Noriega, F. L. Velarde, and J.-P. Richalet, "Pulmonary hypertension in highaltitude chronic hypoxia: response to nifedipine," European Respiratory Journal, vol. 12, no. 5, pp. 1181-1185, 1998.

[45] G. Manier, H. Guenard, Y. Castaing, N. Varene, and E. Vargas, "Pulmonary gas exchange in Andean natives with excessive polycythemia-effect of hemodilution," Journal of Applied Physiology, vol. 65, no. 5, pp. 2107-2117, 1988.

[46] A. A. Aldashev, B. K. Kojonazarov, T. A. Amatov et al., "Phosphodiesterase type 5 and high altitude pulmonary hypertension," Thorax, vol. 60, no. 8, pp. 683-687, 2005.

[47] B. Jin, X.-P. Luo, H.-C. Ni, and H.-M. Shi, "Phosphodiesterase type 5 inhibitors for high-altitude pulmonary hypertension: a meta-analysis," Clinical Drug Investigation, vol. 30, no. 4, pp. 259-265, 2010.

[48] J. Andrews, S. Martina, M. Natoli, A. Walker, J. Freiberger, and R. Moon, "The effect of riociguat on gas exchange, exercise performance, and pulmonary artery pressure during acute altitude exposure," in Hypoxia: Translation in Progress, R. C. Roach, P. H. Hackett, and P. D. Wagner, Eds., pp. 728-729, Springer, New York, NY, USA, 1st edition, 2016.

[49] J.-P. Richalet, M. Rivera-Ch, M. Maignan et al., "Acetazolamide for Monge's disease: efficiency and tolerance of 6-month treatment," American Journal of Respiratory and Critical Care Medicine, vol. 177, no. 12, pp. 1370-1376, 2008.

[50] B. Kojonazarov, A. Myrzaakhmatova, T. Sooronbaev, T. Ishizaki, and A. Aldashev, "Effects of fasudil in patients with highaltitude pulmonary hypertension," The European Respiratory Journal, vol. 39, no. 2, pp. 496-498, 2012.

[51] R. D. Seheult, K. Ruh, G. P. Foster, and J. D. Anholm, "Prophylactic bosentan does not improve exercise capacity or lower pulmonary artery systolic pressure at high altitude," Respiratory Physiology and Neurobiology, vol. 165, no. 2-3, pp. 123-130, 2009.

[52] B. Kojonazarov, J. Isakova, B. Imanov et al., "Bosentan reduces pulmonary artery pressure in high altitude residents," High Altitude Medicine and Biology, vol. 13, no. 3, pp. 217-223, 2012.

[53] I. Pham, G. Wuerzner, J. Richalet, S. Peyrard, and M. Azizi, "Bosentan effects in hypoxic pulmonary vasoconstriction: preliminary study in subjects with or without high altitude pulmonary edema-history," Pulmonary Circulation, vol. 2, no. 1, pp. 28-33, 2012.

[54] E. Kortekaas, B. Jaiswal, K. Ruh, G. P. Foster, J. D. Anholm, and J. C. de Graaff, "Effects of high altitude hypoxia and iloprost on right ventricular function in healthy volunteers," Nederlands Tijdschrift Voor Anesthesiologie, vol. 21, no. 4, 6 pages, 2009.

[55] T. G. Smith, N. P. Talbot, C. Privat et al., "Effects of iron supplementation and depletion on hypoxic pulmonary hypertension: two randomized controlled trials," The Journal of the American Medical Association, vol. 302, no. 13, pp. 1444-1450, 2009. 
[56] N. Sommer, I. Strielkov, O. Pak, and N. Weissmann, "Oxygen sensing and signal transduction in hypoxic pulmonary vasoconstriction," European Respiratory Journal, vol. 47, no. 1, pp. 288-303, 2016.

[57] J. T. Sylvester, L. A. Shimoda, P. I. Aaronson, and J. P. T. Ward, "Hypoxic pulmonary vasoconstriction," Physiological Reviews, vol. 92, no. 1, pp. 367-520, 2012.

[58] R. Moudgil, E. D. Michelakis, and S. L. Archer, "Hypoxic pulmonary vasoconstriction," Journal of Applied Physiology, vol. 98, no. 1, pp. 390-403, 2005.

[59] G. B. Waypa and P. T. Schumacker, "Hypoxic pulmonary vasoconstriction: redox events in oxygen sensing," Journal of Applied Physiology, vol. 98, no. 1, pp. 404-414, 2005.

[60] H. A. Ghofrani, I. H. Osterloh, and F. Grimminger, "Sildenafil: from angina to erectile dysfunction to pulmonary hypertension and beyond," Nature Reviews Drug Discovery, vol. 5, no. 8, pp. 689-702, 2006.

[61] A. B. Lumb and P. Slinger, "Hypoxic pulmonary vasoconstriction: physiology and anesthetic implications," Anesthesiology, vol. 122, no. 4, pp. 932-946, 2015.

[62] R. Naeije and S. Brimioulle, "Physiology in medicine: importance of hypoxic pulmonary vasoconstriction in maintaining arterial oxygenation during acute respiratory failure," Critical Care, vol. 5, no. 2, pp. 67-71, 2001.

[63] E. P. Carter, C. L. Hartsfield, M. Miyazono, M. Jakkula, K. G. Morris Jr., and I. F. McMurtry, "Regulation of heme oxygenase1 by nitric oxide during hepatopulmonary syndrome," American Journal of Physiology - Lung Cellular and Molecular Physiology, vol. 283, no. 2, pp. L346-L353, 2002.

[64] R. W. Baumgartner, P. Bartsch, M. Maggiorini, U. Waber, and O. Oelz, "Enhanced cerebral blood flow in acute mountain sickness," Aviation Space and Environmental Medicine, vol. 65, no. 8, pp. 726-729, 1994.

[65] J. B. Jensen, A. D. Wright, N. A. Lassen et al., "Cerebral blood flow in acute mountain sickness," Journal of Applied Physiology, vol. 69, no. 2, pp. 430-433, 1990.

[66] S. C. Sorensen, N. A. Lassen, J. W. Severinghaus, J. Coudert, and M. P. Zamora, "Cerebral glucose metabolism and cerebral blood flow in high-altitude residents," Journal of Applied Physiology, vol. 37, no. 3, pp. 305-310, 1974.

[67] D. M. Bailey, K. A. Evans, P. E. James et al., "Altered free radical metabolism in acute mountain sickness: implications for dynamic cerebral autoregulation and blood-brain barrier function," Journal of Physiology, vol. 587, no. 1, pp. 73-85, 2009.

[68] A. Van Osta, J.-J. Moraine, C. Mélot, H. Mairbäurl, M. Maggiorini, and R. Naeije, "Effects of high altitude exposure on cerebral hemodynamics in normal subjects," Stroke, vol. 36, no. 3, pp. 557-560, 2005.

[69] D. M. Bailey, P. N. Ainslie, S. K. Jackson, R. S. Richardson, and M. Ghatei, "Evidence against redox regulation of energy homoeostasis in humans at high altitude," Clinical Science, vol. 107, no. 6, pp. 589-600, 2004.

[70] D. M. Bailey, B. Davies, and I. S. Young, "Intermittent hypoxic training: implications for lipid peroxidation induced by acute normoxic exercise in active men," Clinical Science, vol. 101, no. 5, pp. 465-475, 2001.

[71] D. M. Bailey, R. Roukens, M. Knauth et al., "Free radicalmediated damage to barrier function is not associated with altered brain morphology in high-altitude headache," Journal of Cerebral Blood Flow and Metabolism, vol. 26, no. 1, pp. 99-111, 2006.
[72] M. C. Tissot Van Patot, G. Leadbetter, L. E. Keyes et al., “Greater free plasma VEGF and lower soluble VEGF receptor-1 in acute mountain sickness," Journal of Applied Physiology, vol. 98, no. 5, pp. 1626-1629, 2005.

[73] K. Kallenberg, D. M. Bailey, S. Christ et al., "Magnetic resonance imaging evidence of cytotoxic cerebral edema in acute mountain sickness," Journal of Cerebral Blood Flow and Metabolism, vol. 27, no. 5, pp. 1064-1071, 2007.

[74] G. G. Schoonman, P. S. Sándor, A. C. Nirkko et al., "Hypoxiainduced acute mountain sickness is associated with intracellular cerebral edema: a $3 \mathrm{~T}$ magnetic resonance imaging study," Journal of Cerebral Blood Flow and Metabolism, vol. 28, no. 1, pp. 198-206, 2008.

[75] H. Green, B. Roy, S. Grant et al., "Downregulation in muscle $\mathrm{Na}^{+}-\mathrm{K}^{+}$-ATPase following a 21-day expedition to $6,194 \mathrm{~m}$," Journal of Applied Physiology, vol. 88, no. 2, pp. 634-640, 2000.

[76] S. Master, J. Gottstein, and A. T. Blei, "Cerebral blood flow and the development of ammonia-induced brain edema in rats after portacaval anastomosis," Hepatology, vol. 30, no. 4, pp. 876-880, 1999.

[77] B. Basnyat and D. R. Murdoch, "High-altitude illness," Lancet, vol. 361, no. 9373, pp. 1967-1974, 2003.

[78] P. H. Hackett, P. R. Yarnell, R. Hill, K. Reynard, J. Heit, and J. McCormick, "High-altitude cerebral edema evaluated with magnetic resonance imaging. Clinical correlation and pathophysiology," Journal of the American Medical Association, vol. 280, no. 22, pp. 1920-1925, 1998.

[79] K. Kallenberg, C. Dehnert, A. Dörfler et al., "Microhemorrhages in nonfatal high-altitude cerebral edema," Journal of Cerebral Blood Flow and Metabolism, vol. 28, no. 9, pp. 1635-1642, 2008.

[80] C. Dehnert, F. Risse, S. Ley et al., "Magnetic resonance imaging of uneven pulmonary perfusion in hypoxia in humans," American Journal of Respiratory and Critical Care Medicine, vol. 174, no. 10, pp. 1132-1138, 2006.

[81] S. R. Hopkins, J. Garg, D. S. Bolar, J. Balouch, and D. L. Levin, "Pulmonary blood flow heterogeneity during hypoxia and highaltitude pulmonary edema," American Journal of Respiratory and Critical Care Medicine, vol. 171, no. 1, pp. 83-87, 2005.

[82] E. R. Swenson, M. Maggiorini, S. Mongovin et al., "Pathogenesis of high-altitude pulmonary edema: inflammation is not an etiologic factor," Journal of the American Medical Association, vol. 287, no. 17, pp. 2228-2235, 2002.

[83] P. Vock, M. H. Brutsche, A. Nanzer, and P. Bartsch, "Variable radiomorphologic data of high altitude pulmonary edema. Features from 60 patients," Chest, vol. 100, no. 5, pp. 1306-1311, 1991.

[84] R. B. Schoene, P. H. Hackett, W. R. Henderson et al., "Highaltitude pulmonary edema: characteristics of lung lavage fluid," Journal of the American Medical Association, vol. 256, no. 1, pp. 63-69, 1986.

[85] C. Dehnert, E. Grünig, D. Mereles, N. von Lennep, and P. Bärtsch, "Identification of individuals susceptible to highaltitude pulmonary oedema at low altitute," European Respiratory Journal, vol. 25, no. 3, pp. 545-551, 2005.

[86] E. Grünig, D. Mereles, W. Hildebrandt et al., "Stress doppler echocardiography for identification of susceptibility to high altitude pulmonary edema," Journal of the American College of Cardiology, vol. 35, no. 4, pp. 980-987, 2000.

[87] G. Hartmann, M. Tschöp, R. Fischer et al., "High altitude increases circulating interleukin-6, interleukin-1 receptor antagonist and C-reactive protein," Cytokine, vol. 12, no. 3, pp. 246-252, 2000. 
[88] K. S. Brar and M. K. Garg, "High altitude-induced pituitary apoplexy," Singapore Medical Journal, vol. 53, no. 6, pp. el17-e119, 2012.

[89] C. Imray, "Acetazolamide for the prophylaxis of acute mountain sickness," British Medical Journal, vol. 345, Article ID e7077, 2012.

[90] S. R. Muza, B. A. Beidleman, and C. S. Fulco, "Altitude preexposure recommendations for inducing acclimatization," High Altitude Medicine and Biology, vol. 11, no. 2, pp. 87-92, 2010.

[91] E. V. Low, A. J. Avery, V. Gupta, A. Schedlbauer, and M. P. W. Grocott, "Identifying the lowest effective dose of acetazolamide for the prophylaxis of acute mountain sickness: systematic review and meta-analysis," British Medical Journal, vol. 345, no. 7881, Article ID e6779, 2012.

[92] A. B. Montgomery, J. M. Luce, P. Michael, and J. Mills, "Effects of dexamethasone on the incidence of acute mountain sickness at two intermediate altitudes," The Journal of the American Medical Association, vol. 261, no. 5, pp. 734-736, 1989.

[93] A. J. Ellsworth, E. B. Larson, and D. Strickland, "A randomized trial of dexamethasone and acetazolamide for acute mountain sickness prophylaxis," The American Journal of Medicine, vol. 83, no. 6, pp. 1024-1030, 1987.

[94] A. M. Luks, S. E. McIntosh, C. K. Grissom et al., "Wilderness medical society consensus guidelines for the prevention and treatment of acute altitude illness," Wilderness and Environmental Medicine, vol. 21, no. 2, pp. 146-155, 2010.

[95] B. Kayser, R. Hulsebosch, and F. Bosch, "Low-dose acetylsalicylic acid analog and acetazolamide for prevention of acute mountain sickness," High Altitude Medicine and Biology, vol. 9, no. 1, pp. 15-23, 2008.

[96] C. Imray, A. Wright, A. Subudhi, and R. Roach, "Acute mountain sickness: pathophysiology, prevention, and treatment," Progress in Cardiovascular Diseases, vol. 52, no. 6, pp. 467-484, 2010.

[97] C.-R. Zheng, G.-Z. Chen, J. Yu et al., "Inhaled budesonide and oral dexamethasone prevent acute mountain sickness," The American Journal of Medicine, vol. 127, no. 10, pp. 1001-1009.e2, 2014.

[98] K. L. Clearie, P. A. Williamson, K. Meldrum et al., "Pharmacokinetic and pharmacodynamic comparison of hydrofluoroalkane and chlorofluorocarbon formulations of budesonide," British Journal of Clinical Pharmacology, vol. 71, no. 4, pp. 504-513, 2011.

[99] S. Lähelmä, M. Kirjavainen, M. Kela et al., "Equivalent lung deposition of budesonide in vivo: a comparison of dry powder inhalers using a pharmacokinetic method," British Journal of Clinical Pharmacology, vol. 59, no. 2, pp. 167-173, 2005.

[100] D. Czock, F. Keller, F. M. Rasche, and U. Häussler, "Pharmacokinetics and pharmacodynamics of systemically administered glucocorticoids," Clinical Pharmacokinetics, vol. 44, no. 1, pp. 61-98, 2005.

[101] M. Urner, I. K. Herrmann, C. Booy, B. Roth-Z' Graggen, M. Maggiorini, and B. Beck-Schimmer, "Effect of hypoxia and dexamethasone on inflammation and ion transporter function in pulmonary cells," Clinical and Experimental Immunology, vol. 169, no. 2, pp. 119-128, 2012.

[102] S. L. Young, Y.-S. Ho, and R. A. Silbajoris, "Surfactant apoprotein in adult rat lung compartments is increased by dexamethasone," American Journal of Physiology-Lung Cellular and Molecular Physiology, vol. 260, no. 2, part 1, pp. L161-L167, 1991.

[103] T. J. Stelzner, R. F. O’Brien, K. Sato, and J. V. Weil, "Hypoxiainduced increases in pulmonary transvascular protein escape in rats. Modulation by glucocorticoids," The Journal of Clinical Investigation, vol. 82, no. 6, pp. 1840-1847, 1988.

[104] R. B. Schoene, "Dexamethason: by safe means, by fair means," High Altitude Medicine and Biology, vol. 6, no. 4, pp. 273-275, 2005.

[105] R. B. Schoene, "Illnesses at high altitude," Chest, vol. 134, no. 2, pp. 402-416, 2008.

[106] M. Maggiorini, H.-P. Brunner-La Rocca, S. Peth et al., "Both tadalafil and dexamethasone may reduce the incidence of highaltitude pulmonary edema: a randomized trial," Annals of Internal Medicine, vol. 145, no. 7, pp. 497-506, 2006.

[107] N. Netzer, K. Strohl, M. Faulhaber, H. Gatterer, and M. Burtscher, "Hypoxia-related altitude illnesses," Journal of Travel Medicine, vol. 20, no. 4, pp. 247-255, 2013.

[108] J. F. Kasic, M. Yaron, R. A. Nicholas, J. A. Lickteig, and R. Roach, "Treatment of acute mountain sickness: hyperbaric versus oxygen therapy," Annals of Emergency Medicine, vol. 20, no. 10, pp. 1109-1112, 1991.

[109] K. Freeman, M. Shalit, and G. Stroh, "Use of the Gamow Bag by EMT-basic park rangers for treatment of high-altitude pulmonary edema and high-altitude cerebral edema," Wilderness and Environmental Medicine, vol. 15, no. 3, pp. 198-201, 2004.

[110] R. Naeije and C. Dedobbeleer, "Pulmonary hypertension and the right ventricle in hypoxia," Experimental Physiology, vol. 98, no. 8, pp. 1247-1256, 2013.

[111] K. R. Stenmark, B. Meyrick, N. Galie, W. J. Mooi, and I. F. McMurtry, "Animal models of pulmonary arterial hypertension: the hope for etiological discovery and pharmacological cure," American Journal of Physiology-Lung Cellular and Molecular Physiology, vol. 297, no. 6, pp. L1013-L1032, 2009.

[112] K. R. Stenmark, K. A. Fagan, and M. G. Frid, "Hypoxia-induced pulmonary vascular remodeling: cellular and molecular mechanisms," Circulation Research, vol. 99, no. 7, pp. 675-691, 2006.

[113] O. Pak, A. Aldashev, D. Welsh, and A. Peacock, "The effects of hypoxia on-the cells of the pulmonary vasculature," European Respiratory Journal, vol. 30, no. 2, pp. 364-372, 2007.

[114] F. Grimminger and R. T. Schermuly, "PDGF receptor and its antagonists: role in treatment of $\mathrm{PAH}$, Advances in Experimental Medicine and Biology, vol. 661, pp. 435-446, 2010.

[115] R. T. Schermuly, E. Dony, H. A. Ghofrani et al., "Reversal of experimental pulmonary hypertension by PDGF inhibition," Journal of Clinical Investigation, vol. 115, no. 10, pp. 2811-2821, 2005.

[116] H. Ghofrani, M. Humbert, D. Langleben et al., "Riociguat: mode of action and clinical development in pulmonary hypertension," Chest, vol. 151, no. 2, pp. 468-480, 2017.

[117] N. Weissmann, S. Hackemack, B. K. Dahal et al., "The soluble guanylate cyclase activator HMR1766 reverses hypoxia-induced experimental pulmonary hypertension in mice," American Journal of Physiology - Lung Cellular and Molecular Physiology, vol. 297, no. 4, pp. L658-L665, 2009.

[118] G. L. Semenza, "HIF-1: mediator of physiological and pathophysiological responses to hypoxia," Journal of Applied Physiology, vol. 88, no. 4, pp. 1474-1480, 2000.

[119] A. Y. Yu, L. A. Shimoda, N. V. Iyer et al., "Impaired physiological responses to chronic hypoxia in mice partially deficient for hypoxia-inducible factor $1 \alpha$," Journal of Clinical Investigation, vol. 103, no. 5, pp. 691-696, 1999.

[120] P. Dromparis and E. D. Michelakis, "Mitochondria in vascular health and disease," Annual Review of Physiology, vol. 75, pp. 95-126, 2013. 
[121] P. Dromparis, G. Sutendra, and E. D. Michelakis, "The role of mitochondria in pulmonary vascular remodeling," Journal of Molecular Medicine, vol. 88, no. 10, pp. 1003-1010, 2010.

[122] G. Sutendra, P. Dromparis, P. Wright et al., "The role of nogo and the mitochondria-endoplasmic reticulum unit in pulmonary hypertension," Science Translational Medicine, vol. 3, no. 88, p. 88ra55, 2011.

[123] M. S. McMurtry, S. Bonnet, X. Wu et al., "Dichloroacetate prevents and reverses pulmonary hypertension by inducing pulmonary artery smooth muscle cell apoptosis," Circulation Research, vol. 95, no. 8, pp. 830-840, 2004.

[124] X. Huang, L. Zou, X. Yu et al., "Salidroside attenuates chronic hypoxia-induced pulmonary hypertension via adenosine A2a receptor related mitochondria-dependent apoptosis pathway," Journal of Molecular and Cellular Cardiology, vol. 82, pp. 153166, 2015.

[125] N. S. Chandel, D. S. McClintock, C. E. Feliciano et al., "Reactive oxygen species generated at mitochondrial Complex III stabilize hypoxia-inducible factor- $1 \alpha$ during hypoxia: a mechanism of $\mathrm{O} 2$ sensing," Journal of Biological Chemistry, vol. 275, no. 33, pp. 25130-25138, 2000.

[126] S. L. Archer, M. Gomberg-Maitland, M. L. Maitland, S. Rich, J. G. N. Garcia, and E. K. Weir, "Mitochondrial metabolism, redox signaling, and fusion: a mitochondria-ROS-HIF- $1 \alpha-\mathrm{Kv} 1.5 \mathrm{O}_{2}$ sensing pathway at the intersection of pulmonary hypertension and cancer," American Journal of Physiology-Heart and Circulatory Physiology, vol. 294, no. 2, pp. H570-H578, 2008.

[127] V. Lachmanová, O. Hnliličková, V. Povýšilová, V. Hampl, and J. Herget, "N-acetylcysteine inhibits hypoxic pulmonary hypertension most effectively in the initial phase of chronic hypoxia," Life Sciences, vol. 77, no. 2, pp. 175-182, 2005.

[128] B. Elmedal, M. Y. De Dam, M. J. Mulvany, and U. Simonsen, "The superoxide dismutase mimetic, tempol, blunts right ventricular hypertrophy in chronic hypoxic rats," British Journal of Pharmacology, vol. 141, no. 1, pp. 105-113, 2004.

[129] S. E. Adesina, B.-Y. Kang, K. M. Bijli et al., "Targeting mitochondrial reactive oxygen species to modulate hypoxia-induced pulmonary hypertension," Free Radical Biology and Medicine, vol. 87, pp. 36-47, 2015.

[130] M. Aldenderfer, "Peopling the tibetan plateau: insights from archaeology," High Altitude Medicine and Biology, vol. 12, no. 2, pp. 141-147, 2011.

[131] R. Naeije and R. Vanderpool, "Pulmonary hypertension and chronic mountain sickness," High Altitude Medicine and Biology, vol. 14, no. 2, pp. 117-125, 2013.

[132] N. Petousi and P. A. Robbins, "Human adaptation to the hypoxia of high altitude: the Tibetan paradigm from the pregenomic to the postgenomic era," Journal of Applied Physiology, vol. 116, no. 7, pp. 875-884, 2014.

[133] A. Lockhart, M. Zelter, J. Mensch-Dechene et al., "Pressureflow-volume relationships in pulmonary circulation of normal highlanders," Journal of Applied Physiology, vol. 41, no. 4, pp. 449-456, 1976.

[134] N. Banchero, F. Sime, D. Peñaloza, J. Cruz, R. Gamboa, and E. Marticorena, "Pulmonary pressure, cardiac output, and arterial oxygen saturation during exercise at high altitude and at sea level," Circulation, vol. 33, no. 2, pp. 249-262, 1966.

[135] T. Stuber, C. Sartori, M. Schwab et al., "Exaggerated pulmonary hypertension during mild exercise in chronic mountain sickness," Chest, vol. 137, no. 2, pp. 388-392, 2010.
[136] H. Groepenhoff, M. J. Overbeek, M. Mulè et al., "Exercise pathophysiology in patients with chronic mountain sickness," Chest, vol. 142, no. 4, pp. 877-884, 2012.

[137] F. Sime, D. Peñaloza, and L. Ruiz, "Bradycardia, increased cardiac output, and reversal of pulmonary hypertension in altitude natives living at sea level," British Heart Journal, vol. 33, no. 5, pp. 647-657, 1971.

[138] S. C. Erzurum, S. Ghosh, A. J. Janocha et al., "Higher blood flow and circulating NO products offset high-altitude hypoxia among Tibetans," Proceedings of the National Academy of Sciences of the United States of America, vol. 104, no. 45, pp. 17593-17598, 2007.

[139] B. D. Hoit, N. D. Dalton, S. C. Erzurum, D. Laskowski, K. P. Strohl, and C. M. Beall, "Nitric oxide and cardiopulmonary hemodynamics in Tibetan highlanders," Journal of Applied Physiology, vol. 99, no. 5, pp. 1796-1801, 2005.

[140] X. Yi, Y. Liang, E. Huerta-Sanchez et al., "Sequencing of 50 human exomes reveals adaptation to high altitude," Science, vol. 329, no. 5987, pp. 75-78, 2010.

[141] T. S. Simonson, Y. Yang, C. D. Huff et al., "Genetic evidence for high-altitude adaptation in Tibet," Science, vol. 329, no. 5987, pp. 72-75, 2010.

[142] F. R. Lorenzo, C. Huff, M. Myllymäki et al., "A genetic mechanism for Tibetan high-altitude adaptation," Nature Genetics, vol. 46, no. 9, pp. 951-956, 2014.

[143] D. Yang, Y. Peng, Ouzhuluobu et al., "HMOX2 functions as a modifier gene for high-altitude adaptation in Tibetans," Human Mutation, vol. 37, no. 2, pp. 216-223, 2016.

[144] C. M. Beall, G. L. Cavalleri, L. Deng et al., "Natural selection on EPAS1 (HIF2 $\alpha$ ) associated with low hemoglobin concentration in Tibetan highlanders," Proceedings of the National Academy of Sciences of the United States of America, vol. 107, no. 25, pp. 11459-11464, 2010.

[145] L. B. Scheinfeldt, S. Soi, S. Thompson et al., "Genetic adaptation to high altitude in the Ethiopian highlands," Genome Biology, vol. 13, no. 1, article R1, 2012.

[146] E. Huerta-Sánchez, M. DeGiorgio, L. Pagani et al., "Genetic signatures reveal high-altitude adaptation in a set of ethiopian populations," Molecular Biology and Evolution, vol. 30, no. 8, pp. 1877-1888, 2013.

[147] R. Naeije, "Physiological adaptation of the cardiovascular system to high altitude," Progress in Cardiovascular Diseases, vol. 52, no. 6, pp. 456-466, 2010.

[148] J. H. K. Vogel, W. F. Weaver, R. L. Rose, S. G. Blount, and R. F. Grover, "Pulmonary hypertension on exertion in normal men living at 10159 feet (Leadville, Colorado)," Medicina Thoracalis, vol. 19, pp. 269-285, 1962.

[149] S. Huez, K. Retailleau, P. Unger et al., "Right and left ventricular adaptation to hypoxia: a tissue Doppler imaging study," American Journal of Physiology-Heart and Circulatory Physiology, vol. 289, no. 4, pp. H1391-H1398, 2005.

[150] S. Huez, V. Faoro, H. Guénard, J.-B. Martinot, and R. Naeije, "Echocardiographic and tissue doppler imaging of cardiac adaptation to high altitude in native highlanders versus acclimatized lowlanders," American Journal of Cardiology, vol. 103, no. 11, pp. 1605-1609, 2009.

[151] Y. Allemann, T. Stuber, S. F. de Marchi et al., "Pulmonary artery pressure and cardiac function in children and adolescents after rapid ascent to 3,450 m," American Journal of Physiology-Heart and Circulatory Physiology, vol. 302, no. 12, pp. H2646-H2653, 2012. 
[152] S. Crnkovic, A. Schmidt, B. Egemnazarov et al., "Functional and molecular factors associated with TAPSE in hypoxic pulmonary hypertension," American Journal of Physiology-Lung Cellular and Molecular Physiology, vol. 311, no. 1, pp. L59-L73, 2016.

[153] W. L. Gleason and E. Braunwald, "Studies on the first derivative of the ventricular pressure pulse in man," The Journal of Clinical Investigation, vol. 41, pp. 80-91, 1962.

[154] M. Stembridge, P. N. Ainslie, J. Donnelly et al., "Cardiac structure and function in adolescent Sherpa; effect of habitual altitude and developmental stage," American Journal of Physiology-Heart and Circulatory Physiology, vol. 310, no. 6, pp. H740-H746, 2016. 


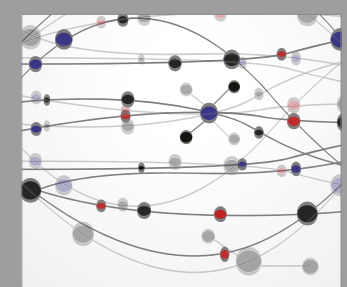

The Scientific World Journal
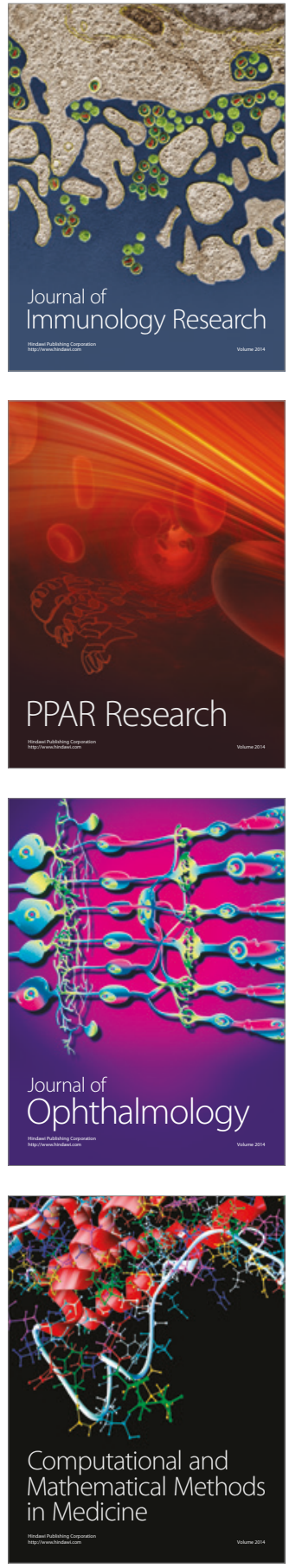

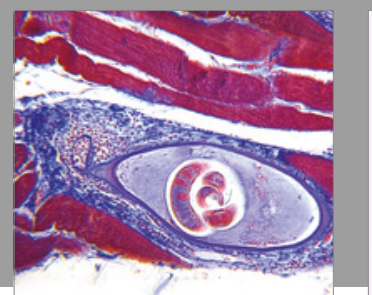

Gastroenterology Research and Practice
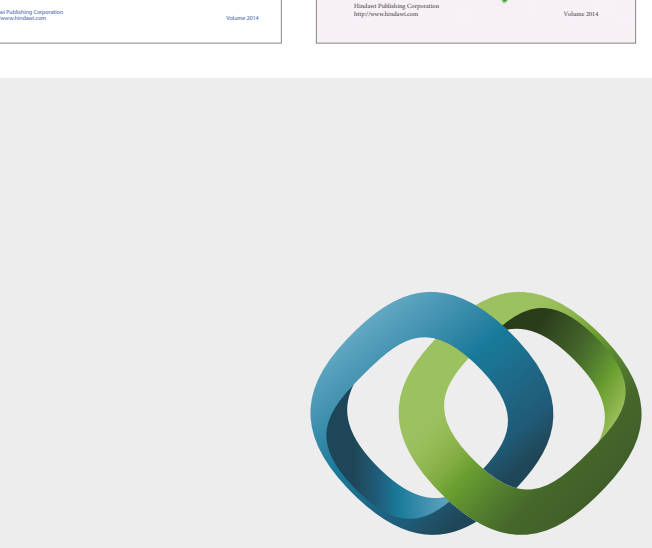

\section{Hindawi}

Submit your manuscripts at

https://www.hindawi.com
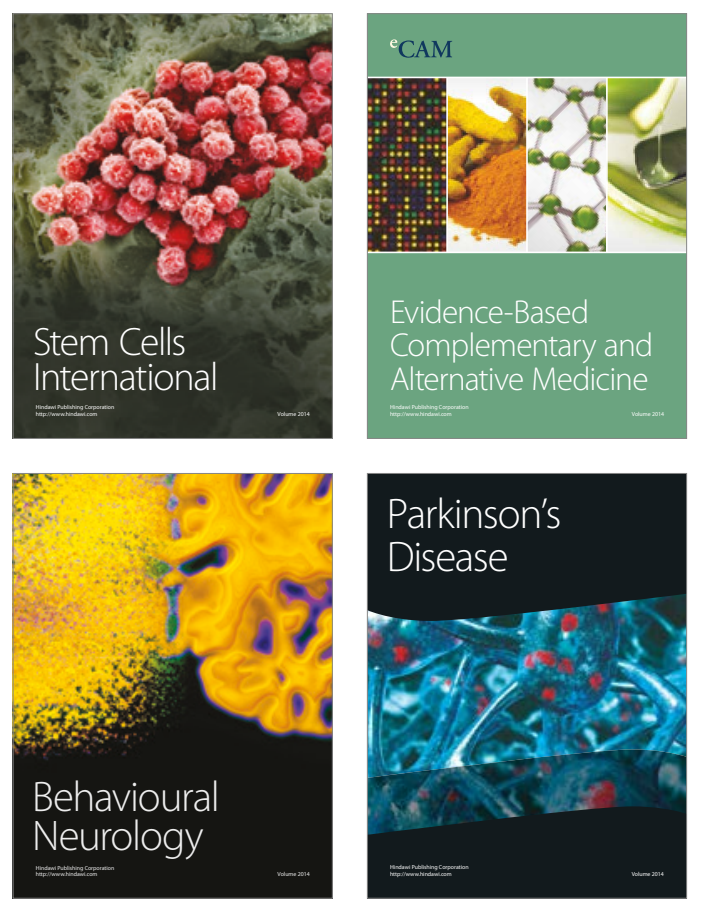
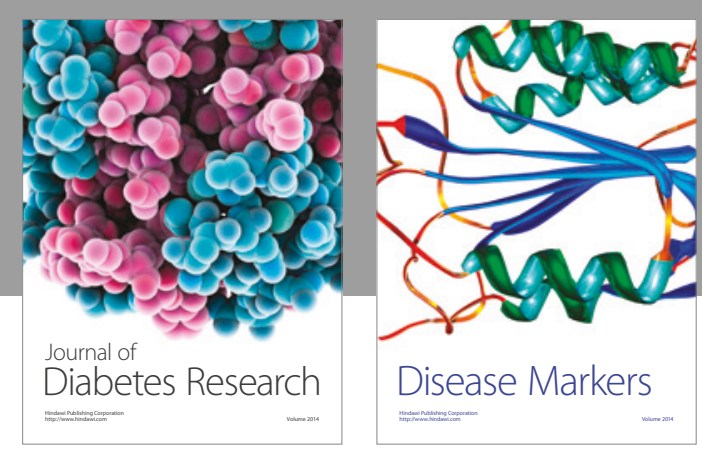

Disease Markers
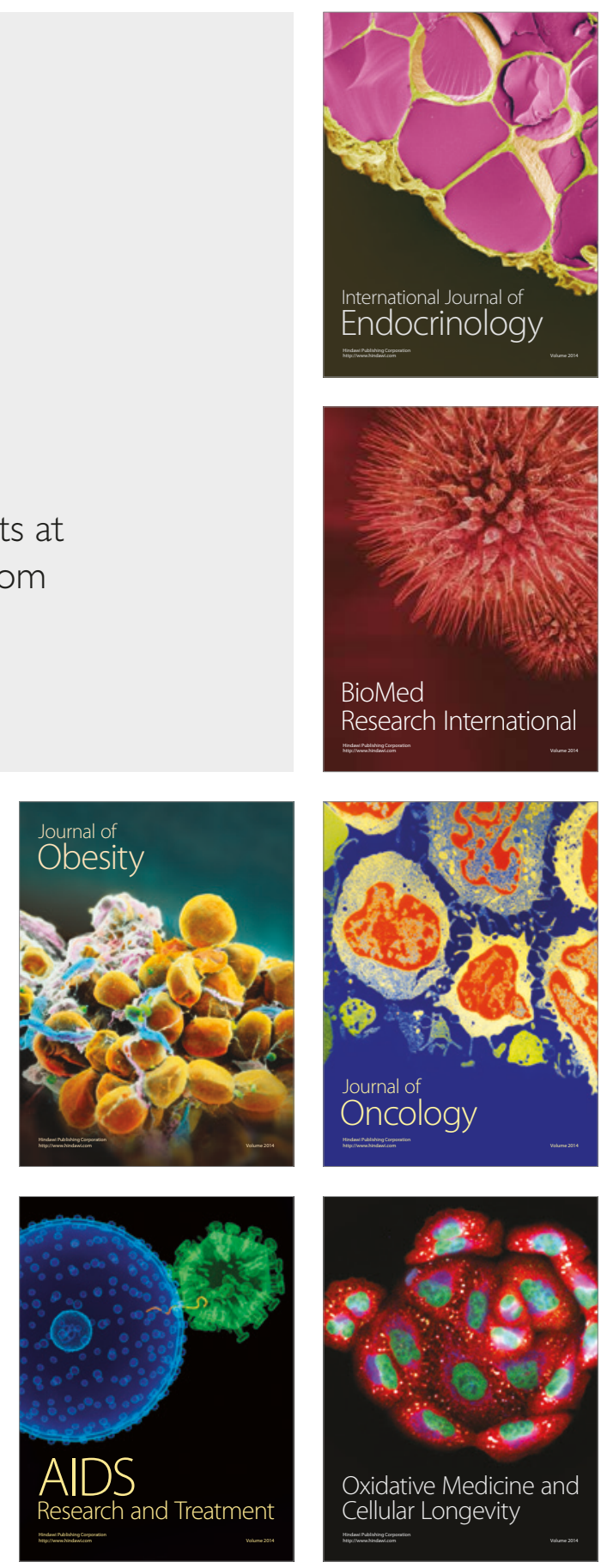